\title{
L'état des connaissances en matière de nutrition des bactéries lactiques
}

\author{
par \\ Michel DESMAZEAUD*
}

\section{Sommaire}

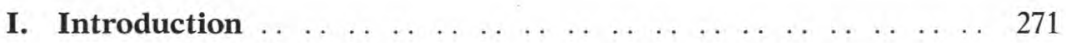

II. Influence de l'oxygène sur la croissance

II.1. Problèmes de la nature aérobie des bactéries lactiques .. 272

II.2. Formation possible de catalase . . . . . . . . . . . . . . . 272

II.3. Respiration et activité NADH-oxydase . . . . . . . . . . . . 273

II.4. Présence de superoxyde dismutase ou d'ions manganèse et tolérance à l'oxygène . . . . . . . . . . . . . . . . . . . . . . . . . . 273

III. Métabolisme des hydrates de carbone

III.1. Activité fermentaire sur le lactose . . . . . . . . . . . . . . . . 274

III.2. Transport des sucres à travers les membranes .. .. . . 274

III.2.1. Transport du lactose . . . .

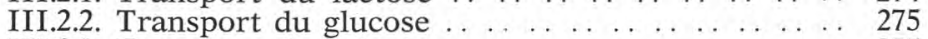

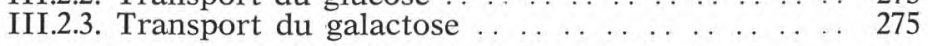

III.3. Catabolisme des sucres . . . .

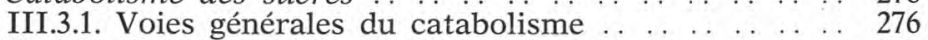

III.3.2. Glycolyse . . . . . . . . . . . . . . . . . . . . . . . . . . . . . . 276

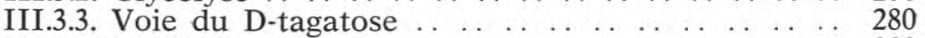

III.3.4. Voie de Leloir . . . . . . . . . . . . . . . . . . . . . . . . . . 280

III.3.5. Voie des pentoses-phosphates . . . . . . . . . . . . . . 281

III.3.6. Régulation du métabolisme et utilisation séquentielle des sucres . . . . . . . . . . . . . . . . 281

III.3.7. Problèmes génétiques du métabolisme du lactose 285

IV. Utilisation du pyruvate et du citrate

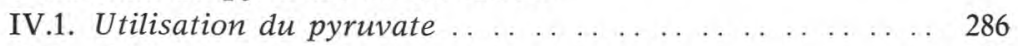

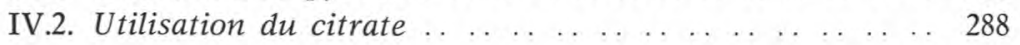

V. Nutrition azotée

V.1. Exigence en acides aminés. Utilisation des acides aminés

libres . . . . . . . . . . . . . . . . . . . . . . . . . . . . . . . . . . . . . . 290

* Institut National de la Recherche Agronomique, Laboratoire de Microbiologie Laitière et Génie Alimentaire - 78350 Jouy-en-Josas (France). 
V.2. Utilisation des peptides .. . . . . . . . . . . . . . . . . . . 292

V.2.1. Utilisation de la fraction non protéique du lait .. 292

V.2.2. Utilisation et transport des peptides exogènes .. 292

V.3. Utilisation des protéines du lait . . . . . . . . . . . . . . . . . . 294

V.4. Mécanismes d'utilisation des peptides et des protéines : activités protéolytiques des bactéries lactiques ... . . . 294

V.4.1. Type d'enzymes protéolytiques trouvées chez les bactéries lactiques et leur localisation cellulaire 294

V.4.1.1. Problèmes méthodologiques ... . . . . . . 294

V.4.1.2. Protéinases et peptidases extracellulaires ou liées aux enveloppes cellulaires...... 296

V.4.1.3. Protéinases et peptidases intracellulaires 298

V.4.2. Facteurs modulant l'activité protéolytique ... . 301

V.4.2.1. Facteurs physiologiques ... . . . . . . . . . . 301

V.4.2.2. Facteurs génétiques .. . . . . . . . . . . . . . 301

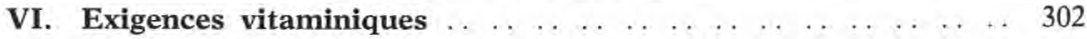

VII. Influence des bases azotées, des minéraux et des acides gras .. 303

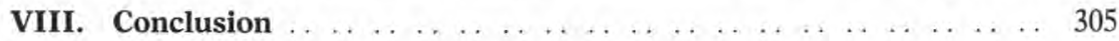

\section{Rés u m é}

Le terme "bactéries lactiques " désigne des bactéries produisant de l'acide lactique par fermentation des hydrates de carbone, tolérant des $\mathrm{pH}$ acides, de niches écologiques anaérobies ou anaérobies facultatives et se montrant catalase négative. L'oxygène peut parfois leur être substrat, mais conduit au peroxyde d'hydrogène qui leur est toxique. Certaines souches possèdent une superoxyde dismutase à manganèse permettant l'élimination des radicaux libres oxygène.

En général, le transport des sucres à travers la membrane cellulaire, met en jeu un système phosphotransférase, phosphorylant le lactose, le glucose ou le galactose, aux dépens de phosphoénol pyruvate. Certaines souches, ou espèces, possèdent de plus un système perméase tirant son énergie de l'hydrolyse de l'ATP. Le lactosephosphate est dégradé par une phospho- $\beta$-galactosidase, puis le glucose en résultant, suivant la voie glycolytique de Embden-MeyerhofParnas. Le galactose-6-phosphate est catabolisé selon la voie du D-tagatose-6-phosphate. Le galactose est dégradé selon la voie de Leloir. Le métabolisme des sucres est soumis à une régulation par des mécanismes de répression et de rétroinhibition. En présence de différents sucres, la bactérie va les cataboliser successivement, dans un certain ordre. Des plasmides sont associés à certaines étapes du métabolisme du lactose.

Le pyruvate peut être à l'origine de produits autres que le lactate. Les différentes étapes du métabolisme ont été précisées. De même, l'utilisation du citrate est désormais bien précisée. Son métabolisme serait aussi lié à un plasmide. 
Les bactéries lactiques exigent la fourniture exogène d'acides aminés pour leur croissance car elles sont incapables d'en effectuer la synthèse à partir d'une source azotée plus simple. La fraction azotée non protéique du lait est en fait une source importante d'azote pour les bactéries lactiques. Des phénomènes de transport de différents peptides ont aussi été mis en évidence. Les protéines du lait sont utilisées grâce à des protéinases liées à la paroi sous l'influence des ions calcium. D'autre part, elles possèdent un riche équipement en aminopeptidases liées aux membranes et, en protéinases et en diverses exopeptidases intracellulaires. La perte simultanée de la fermentation du lactose et de l'activité protéinasique suggère que ces caractères sont liés, et peuvent résider sur un même plasmide.

Enfin, les bactéries lactiques exigent un certain nombre de vitamines, de bases azotées et de minéraux. Dans certains cas, le gaz carbonique serait essentiel pour leur croissance.

Titre abrégé :

Revue : Nutrition des bactéries lactiques.

Mots clés :

Bactéries lactiques - Nutrition - Résistance à l'oxygène - Transport - Catabolisme - Lactose - Glucose - Galactose - Pyruvate - Citrate - Peptides Acides aminés - Activités protéolytiques - Vitamines.

\section{S u m m a ry}

\section{CURRENT STATE OF RESEARCH ON LACTIC ACID BACTERIA NUTRITION}

The lactic acid bacteria group is consisting of Gram-positive, nonsporing, carbohydrate-fermenting lactic acid producers, acid-tolerant, of non-aerobic habit and generally catalase-negative. However, pediococci give a positive catalase reaction and there are positive reactions in other genera. In these cases, catalase reaction derives from two distinct catalases. In other part, some lactic acid bacteria contain high intracellular levels of manganese ions but were devoid of true superoxyde dismutase. Conversely, those which possess this enzyme did not contain high levels of manganese ions. Enzyme and ions serve to scavenge oxygen radical and to protect the cell against the toxic effects of this radical.

The first stage of lactose utilization involves a phospho-enolpyruvate-phosphotransferase system. Lactose phosphate is hydrolysed with phospho- $\beta$-D-galactosidase. Some lactic and bacteria lack a functional lactose phosphotransferase or phospho-ß-galactosidase. They possess a $\beta$-galactosidase. Glucose is fermented via the glycolytic pathway and galactose-6-phosphate via the tagatose-6-phosphate pathway. Some strains metabolize the galactose through the Leloir path- 
way. Fine control of the metabolism of lactose to lactate involves regulation by end products, precursor activation and allosteric enzymes. Pyruvate-kinase and lactate deshydrogenase are key enzymes in lactose metabolism.

Lactic streptococci growing on galactose, ferment it to lactate, formate, acetate and ethanol. Reduced intracellular levels of both fructose 1,6-diphosphate and triose-phosphates appeared to be the main factors involved in the diversion of lactate to the other products. In a medium containing a mixture of lactose, glucose and galactose, galactose is not significantly metabolized until the other sugars have been exhausted from the medium. Fine control of preexisting enzyme systems by catabolite inhibition may afford an explanation for this sequential utilization of sugars. An association between lactose metabolism and extra-chromosomal genes (plasmids) is now well established.

Pyruvate and citrate can be used and converted into a variety of end-products such as lactic acid, acetic acid, acetaldehyde, ethanol, acetoïn, diacetyl and butane-2,3-diol. The formation of lactic acid from pyruvic acid involves only a lactate dehydrogenase. By contrast the formation of the other products involves many enzymes of the "pyruvate dehydrogenase system». Citrate is rapidly metabolized if a fermentable energy source is also present. The biochemical details of the citrate utilization pathway have been elucidated. There is also experimental evidence that citrate metabolism is plasmid linked.

Lactic acid bacteria require for growth certain amino acids which they are unable to synthesize themselves. The low molecular weight peptides in milk are a significant potential source of nitrogen. Cells possess oligopeptide and dipeptide uptake systems. Bacteria produce cell-bound extracellular proteinases which degrade caseins to transportable peptides. Proteinase is located in the cell-wall in the presence of $\mathrm{CaCl}_{2}$. Exopeptidases of diverse specificity are located in the cell surface. Lactic acid bacteria possess also cytoplasmic proteinases and exopeptidases having various specificities. Peptidase activity was not markedly affected by composition of the growth medium. The simultaneous loss of lactose and proteinase activities observed in variants has led to think that these characters are linked and may in some cases reside on the same plasmid. However, the nature of the interrelationship is unclear.

Lactic acid bacteria require various vitamins (notably niacin, pantothenic acid and biotin), metals ( $\mathrm{Fe}^{3+}, \mathrm{Mg}^{2+}, \mathrm{Mo}^{4+}$ and $\mathrm{Se}^{4+}$ ) and in some cases purines and pyrimidines. Carbon dioxide is also essential for the growth.

Key words:

Lactic acid bacteria - Nutrition - Oxygen resistance - Transport - Catabolism Lactose - Glucose - Galactose - Pyruvate - Citrate - Peptides - Amino acids Proteolytic activities - Vitamins. 


\section{INTRODUCTION}

L'industrie laitière française représente une importante industrie de fermentations puisqu'elle produit environ 1,2 million de tonnes de fromages et plus de $500000 \mathrm{t}$ de yaourts par an. Ceci met en jeu environ $1000 \mathrm{t}$ de bactéries (poids humide).

Les connaissances accumulées depuis plusieurs dizaines d'années sur la nutrition et le comportement des bactéries lactiques ont aidé à la mise au point de ces technologies mais de nombreuses recherches doivent encore être conduites pour arriver à une véritable maîtrise industrielle des fabrications. En effet, les bactéries lactiques sont des micro-organismes particulièrement exigeants en nutriments et le lait ne constitue pas pour elles un milieu de culture optimal. Par exemple, une simple addition d'extrait de levure au lait stimule leur croissance (Lawrence et al., 1976). Cette activation a été attribuée à la présence dans l'extrait de levure d'acides aminés libres, de peptides, de purines, de pyrimidines et de composés inorganiques. Cette simple expérience montre donc les besoins nutritionnels complexes des bactéries lactiques.

Deux revues récentes (Accolas et al., 1980 ; Cogan, 1980) ayant traité déjà d'aspects nutritionnels et métaboliques et des propriétés et du comportement en technologie laitière des levains, nous aborderons, dans le présent mémoire, essentiellement l'utilisation des sucres, du pyruvate, du citrate, la nutrition azotée, les besoins en vitamines des bactéries lactiques. Des besoins plus spécifiques en certains facteurs de croissance (minéraux, bases azotées) seront aussi précisés ainsi que l'influence de certains acides gras. Parmi les facteurs physicochimiques, nous aborderons la tolérance à l'oxygène car ce problème a été souvent moins développé dans les publications que d'autres paramètres comme l'effet du $\mathrm{pH}$ ou de la température.

Le groupe désigné sous le vocable "bactéries lactiques 》 dans ce mémoire comprend des espèces :

1. des genres Streptococcus, Pediococcus et Lactobacillus qui convertissent au moins $85 \%$ du glucose utilisé en lactate (bactéries homofermentaires) ;

2. des genres Leuconostoc et Lactobacillus qui forment seulement 1 mol de lactate à partir de chaque mol de glucose utilisé. Du gaz carbonique et de l'éthanol sont aussi produits à partir du reste de la molécule de glucose (bactéries hétérofermentaires) (Garvie, 1980).

Donc, ce groupe est constitué de bactéries à coloration de Gram positive, ne formant pas de spores, produisant de l'acide lactique par fermentation des hydrates de carbone, tolérant des $\mathrm{pH}$ acides (Ingram et Luthi, 1961), de niches écologiques anaérobies ou anaérobies facultatives et se montrant catalase négative. Ces bactéries ne 
sont pas mobiles et ne réduisent pas les nitrates (Ingram, 1975). Les quantités d'acide lactique produites sont extrêmement variables.

\section{L'INFLUENCE DE L'OXYGENE SUR LA CROISSANCE}

\section{II.1. Problèmes de la nature aérobie des bactéries lactiques}

On considère généralement les bactéries lactiques comme des germes anaérobies facultatifs ayant une préférence pour des conditions anaérobies (Whittenbury, 1978). Cependant, cet auteur fait remarquer que les bactéries lactiques sont uniques parmi les bactéries capables de croître en aérobiose, par le fait qu'elles sont incapables de synthétiser des porphyrines (et donc des cytochromes et de la catalase) et qu'apparemment, elles ne sont pas capables de former de l'ATP par la chaîne de transport des électrons (ou phosphorylation oxydative). Si l'oxygène peut parfois leur être substrat, il conduit comme produit final au peroxyde d'hydrogène $\left(\mathrm{H}_{2} \mathrm{O}_{2}\right)$ qui est toujours un produit toxique (Davis, 1963) du fait que dans la plupart des cas, ces bactéries ne peuvent pas normalement le décomposer, ne possédant pas de catalase fonctionnelle.

\section{II.2. Formation possible de catalase}

Il faut noter cependant que des souches de lactobacilles contenant une catalase ont été mises en évidence. Wurtz (1953) a détecté une catalase dans un mutant de Lactobacillus plantarum, Vankova (1957) a trouvé trois souches de $L$. delbrueckii contenant des pigments cytochromiques et une catalase. Enfin, Dacre et Sharpe (1956) ont isolé du fromage de Cheddar trois souches catalase-positive.

Chez les streptocoques, Whittenbury (1964) a montré que si l'on inclut de l'hémine dans le milieu et que l'on incube en aérobiose, beaucoup de bactéries lactiques développent une activité catalasique. Les bactéries lactiques, dans ces conditions, sont en effet capables de synthétiser l'apo-protéine de la catalase et de la lier à l'hémine préformée. Ainsi Streptococcus faecalis, L. casei, L. plantarum, L. brevis, Leuconostoc mesenteroides ou Pediococcus acidilactici forment une catalase si l'hémine leur est fournie (Whittenbury, 1962 ; 1966). Felton et al. (1953) ont montré aussi que des pédiocoques peuvent donner une réaction catalase positive.

Whittenbury (1964) considère que la réaction catalase-positive chez certaines bactéries lactiques met en œuvre deux catalases distinctes d'une part, d'un système non orthodoxe stable au cyanure 
et à l'azoture, et d'autre part, d'une catalase classique sensible à ces poisons mais qui n'est produite que si des composés de type hémine sont disponibles dans le milieu (Ingram, 1975).

\section{II.3. Respiration et activité NADH-oxydase chez des bactéries lactiques}

La phosphorylation oxydative n'est pas en général une propriété du métabolisme producteur d'énergie chez les streptocoques puisqu'ils sont incapables de synthétiser les transporteurs d'électrons, c'est-à-dire des cytochromes (Whittenbury, 1978). Cependant, la phosphorylation oxydative a été mise en évidence en l'absence de cytochromes, chez Streptococcus faecalis (Gallin et Vandemark, 1964 ; Smalley et al., 1968). Chez le même organisme, Faust et Vandemark (1970) ont utilisé le fumarate comme accepteur d'électron pour l'oxydation du NADH par des fractions membranaires. En résumé, Whittenbury (1978) indique que $S$. faecalis est capable en aérobiose de former théoriquement quatre moles d'ATP contrairement aux deux moles normalement formées par la transformation homofermentaire du glucose en acide lactique. Des cytochromes ou des activités NADHoxydase ont par ailleurs été montrés chez Leuconostoc mesenteroides (Sijpesteijn, 1970), S. lactis var. diacetylactis (Ritchey et Seeley, 1976) ou L. plantarum, L. brevis et Pediococcus pentosaceus (Whittenbury, 1964) ou L. plantarum (Gotz et al., 1980 a).

\section{II.4. Présence de superoxyde dismutase ou d'ions manganèse et tolérance à l'oxygène}

La superoxyde dismutase est une enzyme qui catalyse l'élimination des radicaux libres oxygène $\left(\mathrm{O}_{2}^{-}\right)$selon la réaction : $2 \mathrm{O}_{2}{ }^{-}+2 \mathrm{H}^{+} \rightarrow \mathrm{H}_{2} \mathrm{O}_{2}+\mathrm{O}_{2}$. Elle fournit ainsi une certaine défense contre la toxicité de l'oxygène (Fridovich, 1979). Streptococcus lactis comme $S$. faecalis et $S$. pyogenes, possède une superoxyde dismutase à manganèse (Britton et al., 1978). D'autre part, L. plantarum est quelque peu tolérant à l'oxygène grâce au manganèse qu'il contient, celui-ci jouant le même rôle qu'une superoxyde dismutase (Archibald et Fridovitch, 1981 a). Le manganèse protégerait les cellules (Götz et al., 1980 b) car il est oxydé par les radicaux $\mathrm{O}_{2}{ }^{-}$qui ainsi disparaissent. Le manganèse trivalent peut s'accumuler dans les cellules car celles-ci contiennent des pyrophosphates qui le stabilisent (Archibald et Fridovich, 1981 b). Une tolérance à l'oxygène a été établie comme suit pour certaines bactéries : S. faecalis $>$ S. lactis $>$ Pediococcus pentosaceus $>$ L. fermentum $>$ L. plantarum $>$ Leuconostoc mesenteroides $>$ L. casei $>$ L. bulgaricus $>$ L. acidophilus $>$ L. ruminis. Chez les lactobacilles qui sont les germes les moins tolérants à l'oxygène, on ne retrouve ni superoxyde dismutase ni des concentrations élevées en manganèse (Archibald et Fridovich, 1981 b). 


\section{METABOLISME DES HYDRATES DE CARBONE}

\section{III.1. Activité fermentaire sur le lactose}

Le sucre fermentescible du lait est le lactose (disaccharide composé de glucose et de galactose) dont la concentration varie de 4 à $5 \%$. Chez les streptocoques mésophiles, la quantité de lactate formée à la fin de la phase exponentielle de croissance ne dépasse guère $0,42 \%(\operatorname{Cogan}, 1978)$ ce qui représente à peu près $0,41 \%$ de lactose fermenté (Cogan, 1980). Chez les streptocoques thermophiles, cette quantité de lactate peut être de 0,5 à $0,6 \%$ (Bouillanne et Desmazeaud, 1980). Chez les lactobacilles thermophiles, les quantités d'acide lactique formées sont plus fortes (Bouillanne et Desmazeaud, 1981) et les valeurs maximales produites dans le lait sont aussi plus importantes : Lactobacillus bulgaricus et L. lactis $<1,8 \% ;$ L. helveticus 2 à $2,5 \%$ (Accolas et al., 1980). Les formes isomères de l'acide lactique sont aussi différentes selon les espèces : pour les streptocoques mésophiles $\mathrm{L}(+)$; pour les Leuconostoc $\mathrm{D}(-)$; pour L. helveticus, $L$. plantarum et $L$. acidophilus DL ; pour $L$. casei $\mathrm{L}(+)$ et pour L. bulgaricus et L. lactis $\mathrm{D}(-)$ (Sharpe, 1979).

\section{III.2. Transport des sucres à travers les membranes}

\section{III.2.1. TRANSPORT DU LACTOSE}

Chez les streptocoques lactiques, le transport du lactose à travers la membrane cellulaire met en jeu un système phosphotransférase qui phosphoryle le lactose aux dépens du phosphoénol pyruvate. Les études se sont appuyées sur les résultats décrits par Kundig et al. (1964) chez Escherichia coli. Chez les bactéries lactiques un tel système a été mis en évidence par McKay et al. $(1969,1970)$. En effet, chez la souche $S$. lactis $\mathrm{C}_{2} \mathrm{~F}$, le transport du lactose implique deux enzymes (Enz. I et Enz. II), un facteur soluble (F III) spécifique du lactose et une protéine stable à la chaleur ( $\mathrm{HPr}$ ), l'ensemble constituant le système phosphotransférase dépendant du phosphoénol pyruvate (PEP). Il est analogue à celui trouvé chez Staphylococcus aureus (Morse et al., 1968). Les étapes du transfert du phosphate et du lactose peuvent être schématisées comme suit :

Phosphoénol pyruvate + protéine $\mathrm{HPr} \rightleftarrows \mathrm{P}-\mathrm{HPr}+$ Pyruvate (Enzyme I, $\mathrm{Mg}^{++}$).

2P-HPr + Facteur III (Lactose) $\leftrightarrows 2 \mathrm{HPr}+\mathrm{F}$ III (Lactose) 2P.

Facteur III (Lactose) 2P + 2 Lactose $\leftrightarrows 2 \mathrm{~F}$ III (Lactose) + 2 Lactose-P (Enzyme II, $\mathrm{Mg}^{++}$).

L'enzyme II spécifique du lactose est liée à la membrane cellulaire. L'enzyme I et la protéine HPr sont des protéines constitutives alors que l'enzyme II et le facteur III (Lactose) sont induits pendant la croissance en présence de lactose ou de galactose (Cogan, 1980). 
Ainsi, le PEP est le donneur de phosphate et le lactose apparaît dans la cellule sous forme de glucosyl- $\beta$ - $(1,4)$-galactoside-6P (ou encore lactose-P). Il est donc prêt pour être hydrolysé par une $\beta$-D-phosphogalactosidase en glucose et D-galactose-6-phosphate (Lawrence et al., 1976). Chez S. thermophilus, Hemme et al. (1980 a, 1980 b) ont trouvé à la fois des activités $\beta$-galactosidase et phospho- $\beta$-galactosidase, ce qui suggère que le lactose est transporté chez cette espèce par le système classique phosphotransférase. Cependant, Tinson et al. (1982 a) et Greenberg et Mahoney (1982) ne retrouvent qu'une activité $\beta$-galactosidase sur d'autres souches de $S$. thermophilus. Ces derniers auteurs estiment que les faibles hydrolyses de l'ONPG-6P en ONPG qu'ils ont observées, pourraient être dues à une activité phosphatase et concluent que le lactose, chez $S$. thermophilus, est transporté par un système du type des perméases (Anraku, 1978).

\section{III.2.2. TRANSPORT DU GLUCOSE.}

Chez les streptocoques lactiques, la présence d'un système phosphotransférase-phosphoénol pyruvate (PEP) dépendant n'a été mis en évidence que récemment. Lee et al. (1973) trouvaient que, en utilisant des cellules traitées au mélange acétone-toluène, chez $S$. cremoris $\mathrm{HP}$ et $S$. lactis $\mathrm{C}_{2}$, le glucose était phosphorylé à la fois par 1'ATP et le PEP. Chez S. lactis (Thompson, 1978), la capacité de réguler la formation de PEP in vivo a permis la caractérisation du système phosphotransférase pour le glucose. Les données suggèrent qu'une pyruvatekinase (enzyme allostérique réalisant la réaction :

$\mathrm{PEP}+\mathrm{ADP} \leftrightarrows$ pyruvate $+\mathrm{ATP})$ joue un rôle clef dans la régulation de la glycolyse et des fonctions du système phosphotransférase chez S. lactis ML3 (Thompson,1978). Enfin, Tinson et al. (1982 a) indiquent que le glucose peut aussi être transporté par un système perméase dont l'énergie est fournie par l'ATP.

\section{III.2.3. TRANSPORT DU GALACTOSE}

Il est désormais établi que, chez $S$. lactis $\mathrm{ML}_{3}$, le galactose est transporté par deux systèmes séparés (Thompson, 1980) : d'une part, le système phosphotransférase dépendant du phosphoénolpyruvate (Thompson et Thomas, 1977 ; Thompson, 1979) et d'autre part, un système perméase tirant son énergie de l'hydrolyse de l'adénosine5'-triphosphate (Lee et al., 1973). Thompson (1980) caractérise comme suit les deux systèmes : les agents découplants (tétrachlorosalicylanilide et carbonyl-cyanide-m-chloraphénylhydrazine) inhibent la prise de galactose par le système perméase mais sont sans action sur l'activité phosphotransférase. La perméase a une haute affinité pour le galactose, le méthyl- $\beta$-D-thiogalactopyranoside et le méthyl- $\beta$-D-galactopyranoside, mais ne possède que peu (ou pas) d'affinité pour le glucose ou le lactose. Les taux maximums du transport du galactose par les deux systèmes sont semblables, mais le système perméase présente une affinité 10 fois supérieure pour le galactose à celle du 
système phosphotransférase. La prise de galactose est apparemment insensible à la présence des réactifs des groupes sulfhydryles.

\section{III.3. Catabolisme des sucres}

\section{III.3.1. VoIES GÉNÉRALES du CATABOLISME}

A la suite du transport à travers les enveloppes cellulaires, on se trouvera en présence, soit de lactose-phosphate, de glucose-phosphate et de galactose-phosphate, soit de lactose libre, de glucose libre ou de galactose libre. Ces composés seront hydrolysés selon trois voies désormais bien caractérisées (fig. 1) (Bisset et Anderson, 1974 ; Lawrence et al., 1976 ; Thomas et al., 1980) chez les streptocoques et les lactobacilles homofermentaires. Chez les streptocoques mésophiles, le lactose-phosphate est hydrolysé en glucose et galactose-6phosphate par une phospho- 3 -galactosidase. Le glucose est alors dégradé suivant la voie glycolytique de Embden-Meyerhof-Parnas (voie EMP) (Lehninger, 1977). Le galactose-6-phosphate est catabolisé selon la voie du D-tagatose-6-phosphate. Le galactose est dégradé selon la voie de Leloir. L'hydrolyse du lactose est réalisée chez $S$. thermophilus par une $\beta$-galactosidase ou une phospho- $\beta$-galactosidase. L'activité hétéro-fermentaire des Leuconostocs utilise les voies du tagatose-6phosphate et de la glycolyse, mais aussi celle des pentoses-phosphates (fig. 2) (Cogan, 1980). Ainsi chez ces germes, la fermentation du lactose détermine la formation de quantités équi moléculaires de lactate, d'éthanol et de $\mathrm{CO}_{2}$. Environ deux moles de lactate, deux moles d'éthanol et deux moles de $\mathrm{CO}_{2}$ sont formées pour chaque mole de lactose fermenté. Des traces de formiate et d'acétate peuvent également être produites (Cogan, 1980).

III.3.2. Glycolyse (OU VOIE DES HEXOSES-Diphosphates HDP OU VOIE EMP)

Certaines enzymes impliquées dans le métabolisme des sucres ont été purifiées (Lawrence et al., 1976) comme la phospho- $\beta$-galactosidase de S. cremoris HP (Johnson et Mc Donald, 1974). Cette enzyme présente une plus grande affinité pour le substrat synthétique ONPG6-P $\left(\mathrm{K}_{\mathrm{m}}=5,88 \times 10^{-4} \mathrm{M}\right)$ que l'enzyme équivalente de Lactobacillus casei $\left(\mathrm{K}_{\mathrm{m}}=1,59 \times 10^{-3} \mathrm{M}\right)$ (Premi et al., 1972). Le D-galactose-6-phosphate est un faible inhibiteur compétitif. L'activité est relativement résistante au traitement thermique et est maximale de $\mathrm{pH} 5$ à $\mathrm{pH} 8$ pour une plage de températures allant de 45 à $52^{\circ} \mathrm{C}$. Le dithiothreitol, l'EDTA et le citrate stimulent cette activité tandis que les ions $\mathrm{Mg}^{++}$ ou $\mathrm{Li}^{++}$et le p-hydroxymercuribenzoate sont inhibiteurs. Ceci montre l'importance de résidus sulfhydryles pour l'activité enzymatique, alors que la plupart des cations sont sans effet. Son poids moléculaire est estimé à 67600 (Johnson et Mc Donald, 1974). Chez S. thermophilus, Hemme et al. (1980 b) ont déterminé des $\mathrm{pH}$ optimums de 7,7 à 8,1 pour l'activité phospho- $\beta$-galactosidase. Celle-ci est stimulée par le 


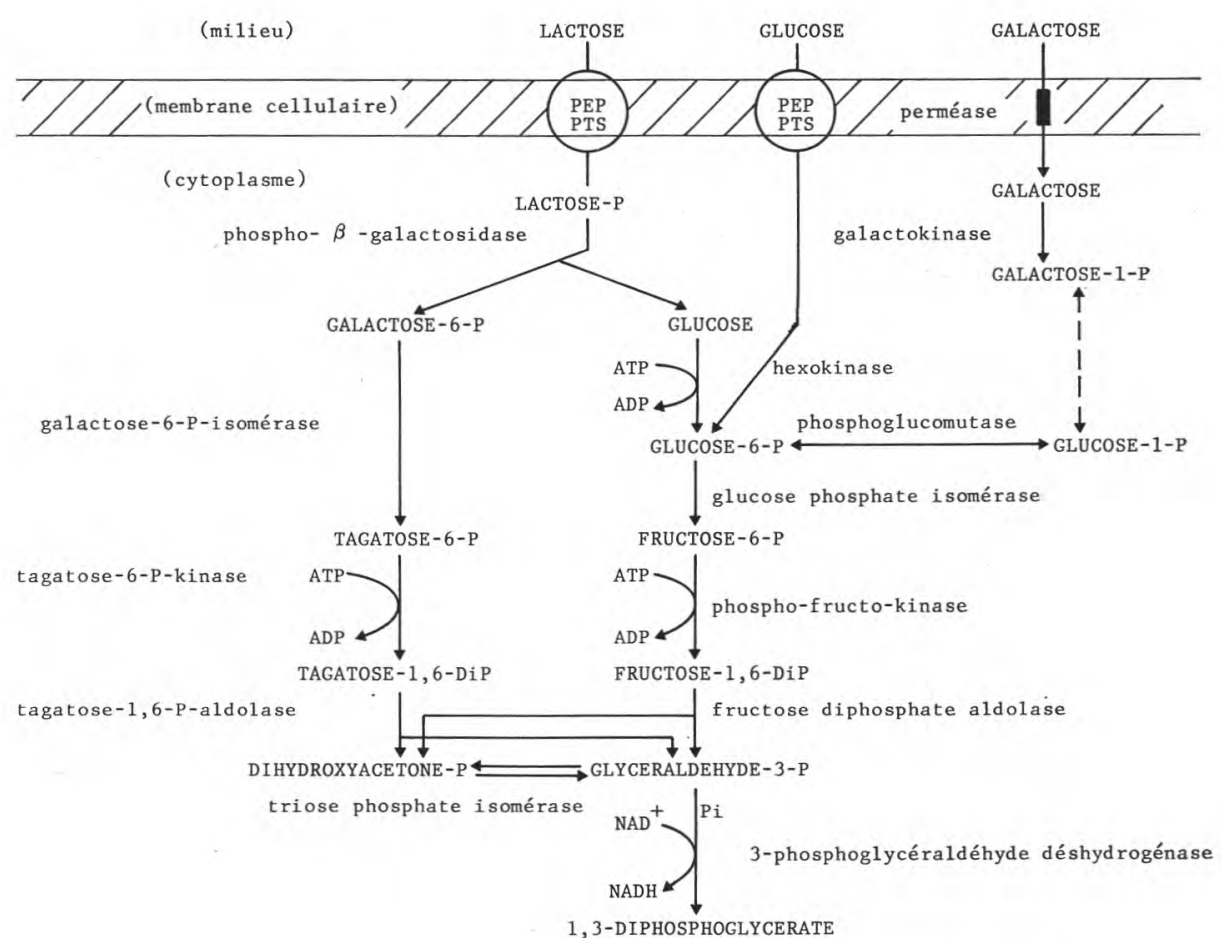

1,3-DIPHOSPHOGLYCERATE

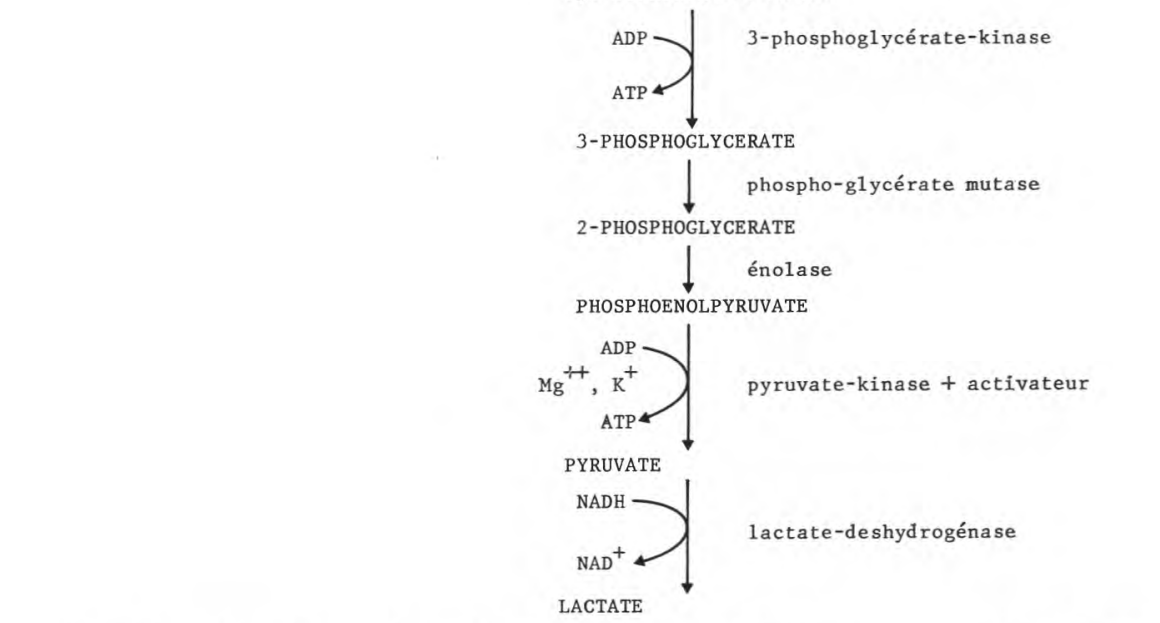

VOIE DU D-TAGATOSE-6-P

VOIE GLYCOLYTIQUE DE EMBDEN-MEYERHOF -
PARNAS (VOie EMP)

VOIE DE LELOIR

fig. 1

Voies principales du transport et du catabolisme du lactose, glucose ou galactose chez les streptocoques homofermentaires (d'après THOMPSON et THOMAS, 1977 ; Cogan, 1980).

$\mathrm{P}=$ phosphate $;$ PEP-PTS $=$ système phosphotransférase-phosphoénol pyruvate dépendant.

Transport and pathways of lactose, glucose or galactose catabolism in homofermentative streptococci (adapted from THOMPSON and THOMAs, 1977 ; Cogan, 1980). $P=$ phosphate $;$ PEP-PTS $=$ phosphoenolpyruvate-dependent phosphotransferase system. 


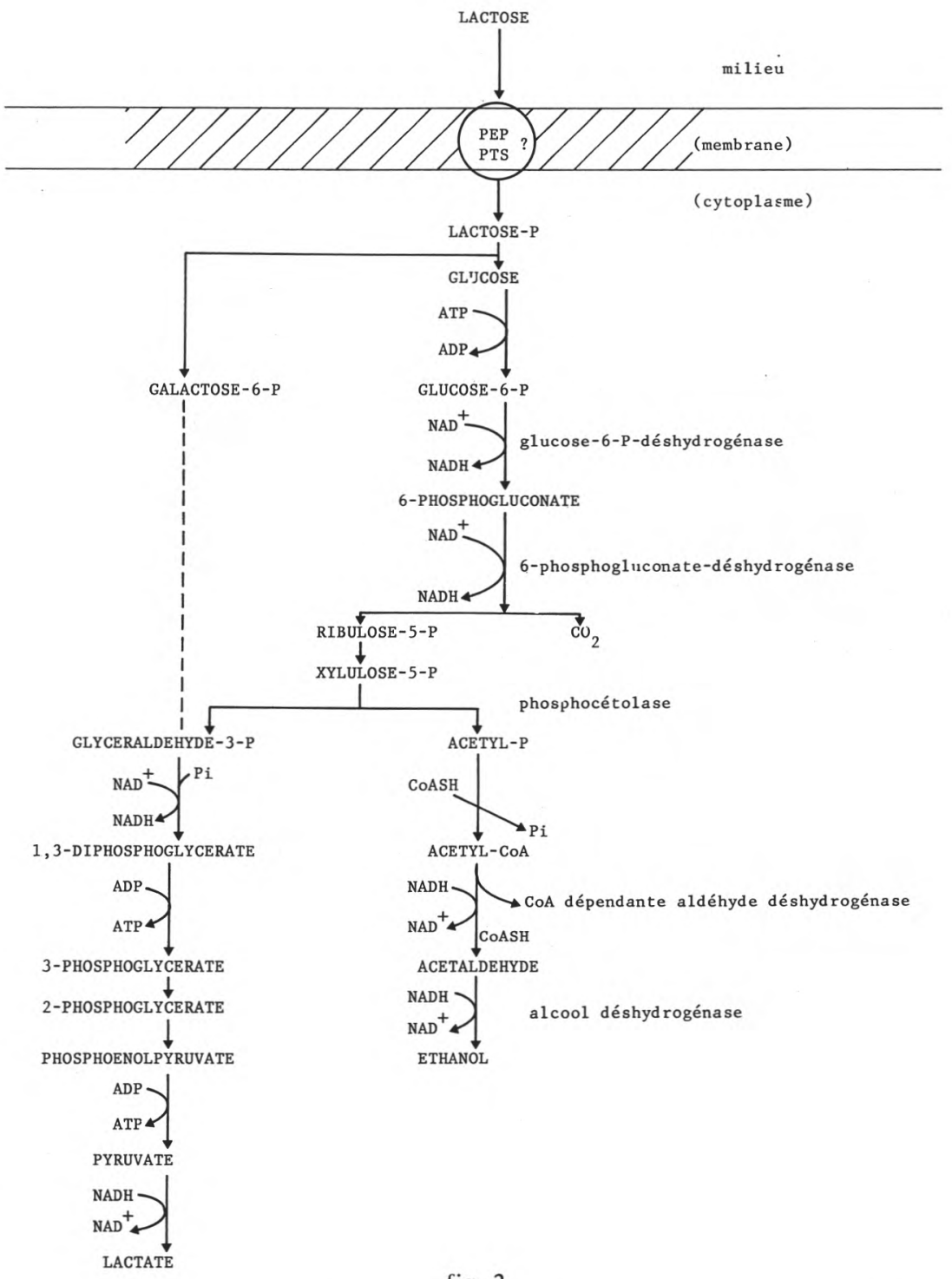

fig. 2

Catabolisme du lactose chez les Leuconostocs (voie hétérofermentaire ou voie hexose monophosphate HMP ou voie des pentoses phosphate) (d'après CoGAN, 1980).

Lactose catabolism in Leuconostoc (heterofermentative pathway) (adapted from Cogan, 1980). 
$\beta$-mercapto-éthanol indiquant certainement une stabilisation de formes multimériques.

D'autre part, chez certaines souches de S. lactis, comme S. lactis ATCC 7962 (Farrow et Garvie, 1979)), le lactose peut être transporté sous forme libre puis hydrolysé par une $\beta$-galactosidase et être alors phosphorylé (Citti et al., 1965). Certaines propriétés de cette enzyme ont été déterminées par Mc Feters et al. (1969). Dans le tampon phosphate à pH 7,0, l'enzyme est instable et se dissocie en deux formes séparables sur Sephadex G 200. Le sulfate d'ammonium 0,85 M stabilise les extraits enzymatiques. L'activité optimale est obtenue à $37,5^{\circ} \mathrm{C}$ et à $\mathrm{pH} 7,05$. Il faut cependant remarquer que la souche S. lactis ATCC 7962 est une souche atypique de cette espèce et qu'elle met en œuvre un système de transport du lactose, lui aussi atypique chez les streptocoques du groupe $\mathrm{N}$.

La pyruvate kinase de S. lactis ML3 a été décrite par Collins et Thomas (1974). Son activité est optimum à $\mathrm{pH} 6,9-7,5$ et elle est inhibée par le phosphate inorganique et les ions sulfate et, dans certaines conditions, par l'adénosine 5'-triphosphate (ATP). Son activité est maximum dans les cellules en croissance exponentielle.

La présence d'autres enzymes glycolytiques a été montrée chez S. lactis : aldolase et glycéraldéhyde-3-phosphate déshydrogénase (Thomas et al., 1974) ; galactokinase, uridine diphosphate glucose épimérase, hexokinase, aldolase, lactate-déshydrogénase (Vakil et Shahani, 1969) ; glucose-6-phosphate-déshydrogénase, 6-phosphogluconique-déshydrogénase (Vakil et Shahani, 1970). Chez S. thermophilus, Hemme et al. (1980 a) ont étudié la variation selon les souches, le $\mathrm{pH}$ du milieu (donc la phase de croissance), la température d'incubation et la source glucidique, de l'équipement en hexokinase, en aldolase, en 3-phosphoglycéraldéhyde déshydrogénase, en pyruvate kinase et en lactate-déshydrogénase.

Les bactéries homofermentaires utilisant la voie EMP dans la dernière étape de la glycolyse, convertissent le pyruvate en lactate et régénèrent ainsi de la nicotinamide adénine dinucléotide (NAD) à partir de la nicotinamide adénine dinucléotide réduite (NADH) formée auparavant. C'est précisément cette étape clef qui permet au cycle de fonctionner. Toutes les bactéries lactiques possèdent donc une lactate-déshydrogénase (Garvie, 1980).

Les lactate-déshydrogénases bactériennes (LDH) ont été très étudiées (revue de Garvie, 1980). Chez les streptocoques lactiques, les recherches ont surtout porté (Jago et al., 1971 ; Dynon et al., 1972 ; Thomas, 1975 ; Thomas et al., 1980) sur S. cremoris. Toutes les souches de streptocoques du groupe N étudiées par Anders et al. (1970) possèdent à la fois des lactate-déshydrogénases NAD- dépendantes ou NAD- indépendantes. Les enzymes NAD- dépendantes sont spécifiques pour l'isomère $\mathrm{L}(+)$ de l'acide lactique. Elles sont fortement activées par le fructose-1,6-diphosphate (FDP). Le phosphate apparaît 
inhiber cette activation. Des propriétés semblables ont été trouvées chez la souche $S$. cremoris US3 par Jonas et al. (1972) après purification partielle d'une $\mathrm{L}(+)$-lactate déshydrogénase NAD- dépendante. Le FDP est essentiel pour la réduction catalytique du pyruvate de pH 5 à 7. Les enzymes NAD-indépendantes (Anders et al., 1970) ne sont pas activées par le fructose 1,6 diphosphate. Certaines sont spécifiques pour l'isomère $\mathrm{L}(+)$ de l'acide lactique et d'autres pour l'isomère $\mathrm{D}(-)$. De même chez S. lactis 760, Mou et al. (1972) ont séparé et purifié deux activités déshydrogénases NAD- dépendantes spécifiques des formes $\mathrm{L}(+)$ ou $\mathrm{D}(-)$ de l'acide lactique. Ces enzymes diffèrent par leur $\mathrm{pH}$ optimum $(8,5$ pour la D-LDH contre 5 à 7 pour la $\mathrm{L}-\mathrm{LDH}$ ), leur stabilité thermique et enfin le $\mathrm{pH}$ et la température auxquels chaque enzyme est formée. La présence d'une racémase de l'acide lactique n'était pas détectée par les méthodes utilisées. Chez S. thermophilus (Garvie, 1978 ; Hemme et al., 1981 a), l'activité lactatedéshydrogénase est indépendante du fructose 1,6-diphosphate mais elle est activée par les ions phosphates. Les ions $\mathrm{Mn}^{++}$inhibent partiellement cette activité mais l'ADP, l'ATP, le 6-P-gluconate, l'oxamate et le NAD sont les inhibiteurs les plus forts de l'activité LDH (dans le sens de la réduction du pyruvate en lactate). L'activité LDH de cette espèce est constante dans une large zone de $\mathrm{pH}(4,7$ à 7,5$)$ mais chute rapidement et devient quasi nulle à $\mathrm{pH}$ 4,6 (Hemme et al., $1981 \mathrm{a}$ ).

\section{III.3.3. VoIE DU D-TAgatose}

Des enzymes de la voie du D-tagatose-6-phosphate ont été mises en évidence chez S. lactis par Bissett et Anderson (1974), chez S. lactis et $S$. cremoris par Thomas et al. (1980). Les enzymes permettant la transformation du galactose-6-phosphate en triose phosphates (par la formation intermédiaire de D-tagatose 6-phosphate et D-tagatose 1,6-diphosphate (TDP) sont la D-galactose 6-phosphate isomérase, la D-tagatose 6-phosphate kinase et la TDP-aldolase. Deux D-cétohexose 1,6-diphosphate aldolases sont présentes chez $S$. cremoris E8 et chez $S$. lactis $\mathrm{C} 10$. Une aldolase qui est induite par la croissance sur lactose ou galactose est active sur le tagatose 1,6-diphosphate et le fructose 1,6-diphosphate (FDP). Cette enzyme, dénommée TDP-aldolase, a les propriétés typiques d'une aldolase de classe I car elle est insensible à l'EDTA et subit une inactivation par le borohydrure de sodium dépendante du substrat. L'autre aldolase a les propriétés caractéristiques d'une aldolase de la classe II. Elle montre une activité avec le FDP mais pas avec le TDP (Crow et Thomas, 1982).

\section{III.3.4. VOIE DE LELOIR}

Les activités de la voie de Leloir ont été décrites chez les streptocoques du groupe N par Bissett et Anderson (1974), Lee et al. (1973), en particulier chez S. lactis par Cords et Mc Kay (1974) et Vakil et Shahani (1969) et chez S. lactis et S. cremoris par Thomas et al. (1980). La voie métabolique est représentée figure 1. 


\section{III.3.5. VOIES DES PENTOSES--PHOSPHATES}

Les enzymes de la voie des pentoses-phosphates sont présentes chez ces organismes (Oram et Reiter, 1966 ; Demko et al., 1972) mais leurs activités spécifiques sont relativement basses (Law, 1982). Ces enzymes effectuant la conversion du glucose 6-phosphate en ribose-5-phosphate fourniraient des pentoses lors de la synthèse des nucléotides ou du NADPH exigé lors de la synthèse des acides gras. Elles n'interviennent que peu dans le métabolisme énergétique (Lawrence et al., 1976 ; Law et Sharpe, 1978).

III.3.6. RÉGULATION DU MÉTABOLISME ET UTILISATION SÉQUENTIELLE DES SUCRES

Le métabolisme des sucres est soumis à une régulation par des mécanismes de répression et de rétroinhibition. La répression agit sur la synthèse des enzymes alors que la rétroinhibition diminue les activités enzymatiques. Lawrence et al. (1976) et Cogan (1980) appellent régulation " grossière » celle qui intervient au niveau de la synthèse des enzymes et régulation "fine " celle qui contrôle l'activité enzymatique. Cogan (1980) décrit comme suit ces mécanismes généraux. "Les gènes structuraux qui codent la synthèse des enzymes inductibles sont normalement inactifs ou réprimés. En présence d'un inducteur, il y a dé-répression parce que l'inducteur réagit avec le répresseur de façon à réduire l'affinité de celui-ci pour une séquence déterminée de l'ADN (l'opérateur) de façon à permettre la transcription et la traduction des gènes structuraux qui aboutit à la synthèse des enzymes correspondantes. Par contre, dans le cas de la rétroinhibition, l'activité d'une enzyme précoce d'une voie métabolique est inhibée par l'un des métabolites terminaux de cette voie. Ce mécanisme joue probablement un rôle plus important que la régulation grossière dans le métabolisme des cellules en phase de croissance, puisque l'enzyme complémentaire soumise à la régulation, est déjà présente dans de telles cellules ». Une fonction de régulation a été attribuée à la pyruvate-kinase des streptocoques lactiques (Thomas, 1976 a) en raison des propriétés de liaisons coopératives de son substrat, le phosphoénol-pyruvate (PEP), et de l'activation allostérique par le fructose di-phosphate (Collins et Thomas, 1974) ou d'autres intermédiaires glycolytiques (Thomas, 1976 b). Le contrôle de l'activité de la pyruvate-kinase peut réguler la concentration du PEP intracellulaire et par conséquent permettre un couplage entre le transport du lactose (par le système phosphotransférase dépendant du PEP) et 1'hydrolyse de celui-ci (fig. 3) (Thomas, 1976 a). Dans des expériences de carence glucidique chez S. lactis, Thompson et Thomas (1977) montrent que les teneurs en 3-phosphoglycérate, 2-phosphoglycérate (2-PG) et PEP augmentent d'une façon notable alors que les autres intermédiaires de la glycolyse diminuent. La capacité des cellules à retenir un " pool » intracellulaire de PEP et de 2-P-G leur confère un pouvoir de survie en leur permettant d'obtenir la quantité nécessaire d'ATP (Thompson et Thomas, 1977). 


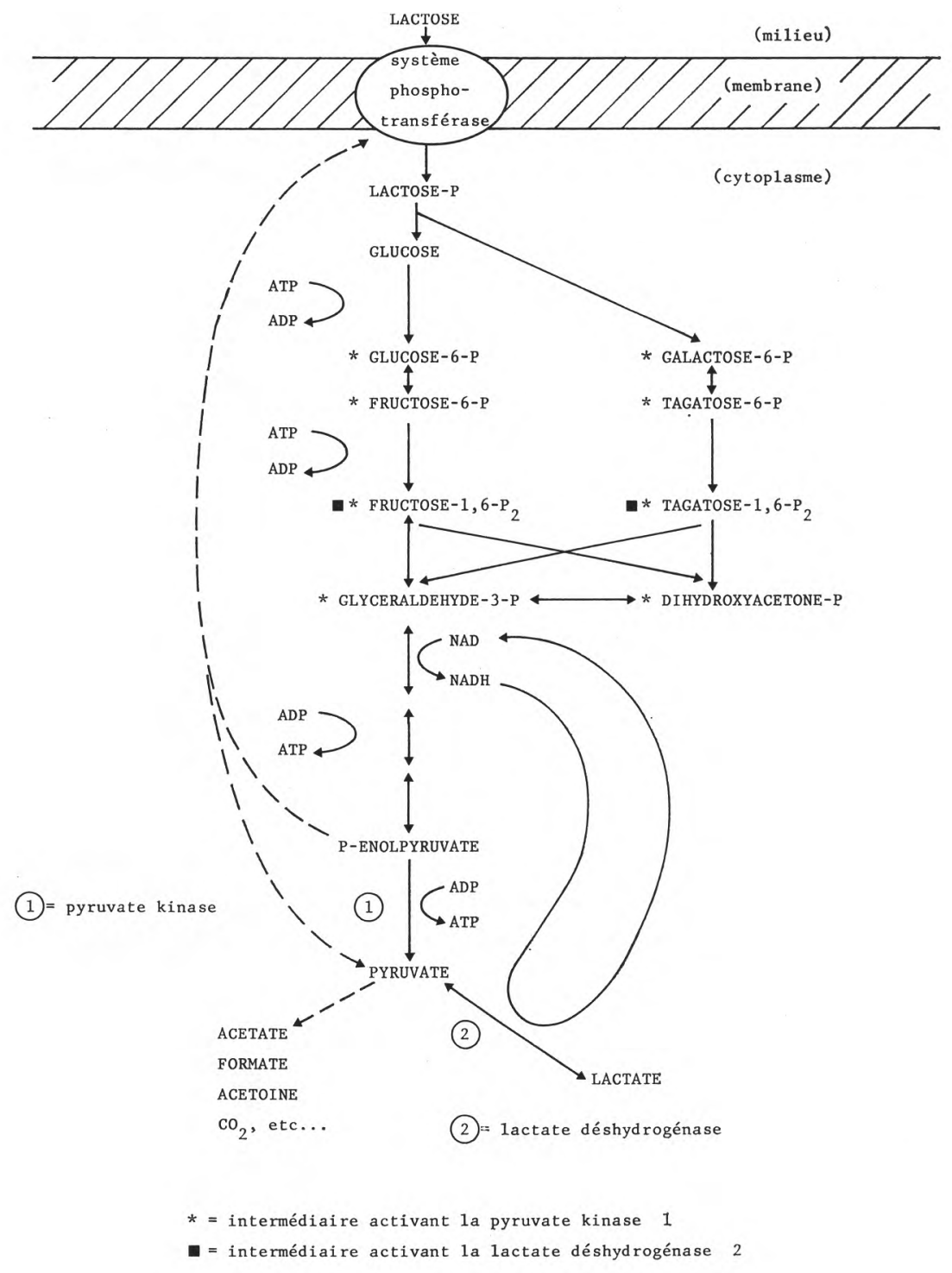

fig. 3

Régulation du catabolisme du lactose chez les streptocoques du groupe $\mathrm{N}$ (d'après THомаs, 1976).

Regulation of lactose catabolism in group $N$ streptococci (adapted from THомAs, 1976). 
Une régulation allostérique agit aussi sur la lactate-déshydrogénase dont l'activité dépend $\mathrm{du} \mathrm{pH}$ et de la présence du fructose di-phosphate ou du tagatose di-phosphate (Thomas, 1976 a). La régulation de cette enzyme fait que, au cours de la croissance exponentielle, les concentrations en pyruvate restent basses, et cela évite le déclenchement des autres étapes métaboliques dérivant du pyruvate (fermentation hétérolactique). La fermentation est donc de type homolactique. Dans ce cas, du lactate est formé par la réaction terminale. La glucolyse peut se poursuivre puisque le coenzyme réduit NADH est réoxydé en $\mathrm{NAD}^{+}$. Celui-ci peut donc être à nouveau mis à contribution dans la chaîne glycolytique (Cogan, 1980).

En présence de différents sucres, la bactérie va les cataboliser successivement dans un certain ordre. Ce "métabolisme séquentiel " des sucres a été étudié par Thompson et al. (1978). Dans le cas de cellules de $S$. lactis ML3 adaptées à une croissance sur galactose puis mises dans un milieu contenant un mélange glucose-galactose-lactose, il a été observé que la croissance de ces cellules était caractérisée initialement par le métabolisme simultané du glucose et du lactose. Le galactose n'était pas utilisé de façon significative jusqu'à ce que les autres sucres présents soient épuisés. L'addition de glucose ou de lactose à une culture de S. lactis ML3 en croissance exponentielle sur galactose entraîne une inhibition immédiate de l'utilisation de ce dernier et une augmentation du taux de croissance concomitante au métabolisme préférentiel du sucre ajouté. Un fait analogue avait déjà été mis en évidence par Bissett et Anderson (1974) lorsqu'ils avaient montré que le glucose réduisait fortement l'activité spécifique des enzymes des voies de Leloir et du tagatose-6-phophate.

Les cellules non proliférantes de S. lactis ML3 obtenues sur galactose (Thompson et al., 1978) métabolisent les trois sucres à des taux identiques. Cependant, les cellules suspendues dans un tampon contenant un mélange de glucose plus galactose ou un mélange de lactose plus galactose consomment encore préférentiellement le glucose ou le lactose. Le taux du métabolisme du galactose est réduit de $95 \%$ en présence du sucre inhibiteur, mais le taux maximum du métabolisme du galactose est retrouvé après épuisement du glucose ou du lactose. Thompson et al. (1978) considèrent que le contrôle fin des activités des systèmes enzymatiques pré-existants, par inhibition catabolique, est une explication satisfaisante rendant compte de l'utilisation séquentielle des sucres. Ainsi, la croissance de différentes souches de streptocoques du groupe $\mathrm{N}$ sur galactose entraîne une transformation de ce sucre en lactate, à raison seulement de 34 à $74 \%$ du sucre présent (Thomas, 1976 a). Enfin, dans une étude récente, Thomas et al. (1980) ont étudié la régulation du métabolisme du galactose chez $S$. lactis et $S$. cremoris. Tous les streptocoques lactiques, à l'exception de la souche $S$. lactis ML8, fermentent le galactose en lactate, formate, acétate et éthanol. Les niveaux intracellulaires du fructose-1,6-diphosphate (FDP), activateur de la lactate- 


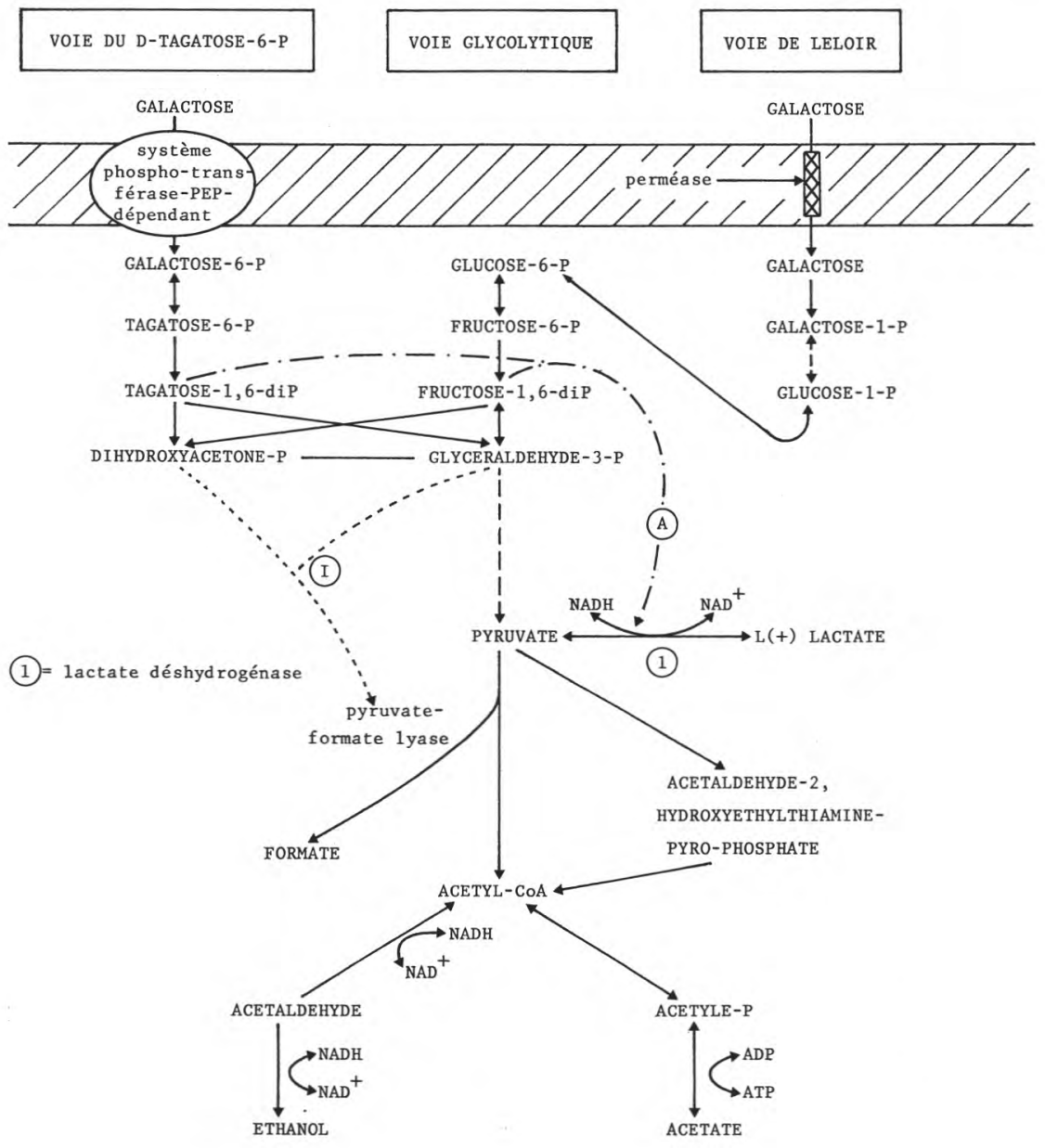

$$
\begin{aligned}
& \text { (A) = sites d'activation } \\
& \text { (I) = sites d'inhibition }
\end{aligned}
$$

fig. 4

Régulation du catabolisme du galactose chez les streptocoques lactiques (d'après THOMAs et al., 1980).

Regulation of galactose catabolism in group $N$ streptococci (adapted from THomas et al., 1980).

déshydrogénase, et des trioses phosphates inhibiteurs de la pyruvatelyase, semblent être les principaux facteurs impliqués dans la production des composés autres que le lactate. S. Lactis produit seulement du lactate à partir du galactose car il maintient des niveaux 
élevés de FDP et de triose phosphates. Les taux de croissance de toutes les souches de $S$. cremoris examinées diminuent fortement pour des concentrations de galactose inférieures à $30 \mathrm{mM}$. Cet effet semble être corrélé avec, d'une part les cinétiques du phénomène de prise (uptake) s'effectuant par un système galactose-phospho-transférase de basse affinité, et avec, d'autre part, les étapes du métabolisme initial s'effectuant par la voie du D-tagatose-6-phosphate. Au contraire, avec 4 des 5 souches de $S$. lactis examinées, la prise de galactose et le métabolisme initial impliquent plutôt une galactose perméase de haute affinité et la voie de Leloir. Pour ces souches, le flux de galactose transitant par les différentes voies est régulé par la concentration exogène en galactose (fig. 4) (Thomas et al., 1980).

Chez $S$. thermophilus, la régulation du métabolisme des sucres a été étudiée par Hemme et al. (1980 a). Le pH est un facteur prépondérant de régulation car il module en particulier l'activité de l'hexokinase. S. thermophilus, contrairement à certaines souches de streptocoques mésophiles (Mc Kay et al., 1971 ; Gilliland et al., 1972), cultive mieux lorsque le milieu contient du lactose que lorsqu'il contient du glucose et du galactose. Donc, il n'y aurait pas chez $S$. thermophilus, d'inhibition catabolique au profit de la source de carbone la plus accessible (Hemme et al., 1980 a).

\section{III.3.7. PRoblèmes GÉNÉTIQUeS du MÉTABolisme du LaCtose}

Les streptocoques du groupe $\mathrm{N}$ produisent spontanément des mutants qui sont incapables d'utiliser le lactose alors que leur croissance est normale sur glucose (Law, 1982). On a montré qu'ils ne possédaient ni les deux protéines composant le système PEP-lactosephospho-transférase ni la phospho- $\beta$-galactosidase (Mc Kay et al., 1970 ; Cords et Mc Kay, 1974), protéines enzymatiques qui peuvent être codées sur un plasmide à ADN (Efstathiou et Mc Kay, 1976 ; Anderson and Mc Kay, 1977). Les problèmes génétiques du métabolisme du lactose chez les bactéries lactiques ont été passés en revue, dans une étude récente, par Davies et Gasson (1981). Trois plasmides sont associés à des étapes semblables du métabolisme du lactose, bien

qu'aucune région d'homologie évidente ne puisse être détectée. En dehors des streptocoques du groupe $\mathrm{N}$, des gènes du métabolisme du lactose ont été associés à des plasmides chez $L$. helveticus subsp jugurti (Smiley et Fryder, 1978), L. casei (Hofer, 1977), L. casei subsp casei (Chassy et al., 1978).

\section{UTILISATION DU PYRUVATE ET DU CITRATE}

Dans certaines conditions, le pyruvate peut être à l'origine de produits autres que le lactate, citons en particulier l'acide acétique, l'acétaldéhyde, l'éthanol, l'acétoïne, le diacétyle et le butane2,3-diol (Colins, 1972 ; Lees et Jago, 1976 ; Broome et al., 1980). Si le 
pyruvate résulte de la glycolyse, comme nous l'avons vu précédemment, il peut aussi provenir de la dégradation de différents acides aminés et des citrates. D'autre part, la production de diacétyle à partir des citrates est une propriété d'une des espèces de streptocoques du groupe N, S. lactis subsp diacetylactis, et de plusieurs espèces de Leuconostoc (Kempler et Mc Kay, 1981).

\section{IV.1. Utilisation du pyruvate}

Alors que la formation de l'acide lactique à partir du pyruvate n'implique qu'une seule enzyme (la lactate-déshydrogénase), la production des composés cités précédemment met en jeu un ensemble d'enzymes : le système pyruvate déshydrogénase (Broome et al., 1980). Ce système avait été pressenti en étudiant l'influence des acides gras sur le métabolisme du pyruvate par les streptocoques lactiques ( $S$. cremoris et S. lactis) (Anders et Jago, 1970). En absence d'acide oléique, le pyruvate était utilisé au maximum à $\mathrm{pH} 4,5$ avec formation d'acétate, d'acétoïne, de diacétyle et de $\mathrm{CO}_{2}$. En présence d'acide oléique, l'utilisation du pyruvate était maximale à $\mathrm{pH} 6,5$, et les seuls produits formés étaient l'acétoïne, le diacétyle et le $\mathrm{CO}_{2}$. Cet effet de l'acide oléique résulterait soit d'une altération de la perméabilité de la membrane cellulaire incapable alors de réguler son $\mathrm{pH}$ intracellulaire indépendamment du $\mathrm{pH}$ extracellulaire (effet observé par Coles et Lichstein en 1963, chez Lactobacillus arabinosus), soit de l'inhibition spécifique d'une enzyme impliquée dans la formation de l'acétate (Anders et Jago, 1970). De plus, ces auteurs ont montré que la voie menant à l'acétate doit être saturée avant que des quantités significatives d'acétoïne et de diacétyle soient formées à partir du pyruvate. Les différentes étapes du métabolisme du pyruvate chez les streptocoques du groupe $\mathrm{N}$ ont été précisées par Thomas et al. en 1979 (cf fig. 5). La pyruvate-décarboxylase catalyse la décarboxylation initiale du pyruvate pour former un complexe actif acétaldéhydeTPP (2, hydroxyéthylthiamine pyrophosphate). Celui-ci réagit alors avec l'acide lipoïque lié de façon covalente à la deuxième enzyme du système : la lipoate acétyltransférase. Celle-ci catalyse le transfert d'un groupe acétyle du complexe acétaldéhyde-TPP au co-enzyme A. Ensuite intervient la lipoyle-déshydrogénase, flavoprotéine catalysant l'oxydation du résidu dihydrolipoyle sur la lipoate acétyle transférase avec réduction concomitante du NADH (Broome et al., 1980). Chez $S$. lactis $\mathrm{C} 10$, ces études sont rendues difficiles par l'instabilité des enzymes du système qui semblent liées à la membrane plasmique par des liaisons labiles. Ces auteurs indiquent que le système pyruvatedéshydrogénase de $S$. faecalis est plutôt proche de celui des mamifères, alors que celui de $S$. lactis se rapprocherait de celui d'Escherichia coli.

En l'absence d'un mécanisme de transport actif, le pyruvate passerait plus facilement dans les cellules de $S$. lactis $\mathrm{C} 10$ à $\mathrm{pH} 5,5$ qu'à $\mathrm{pH}$ 6,5. La prise d'oxygène et la formation d'acétate sont constan- 


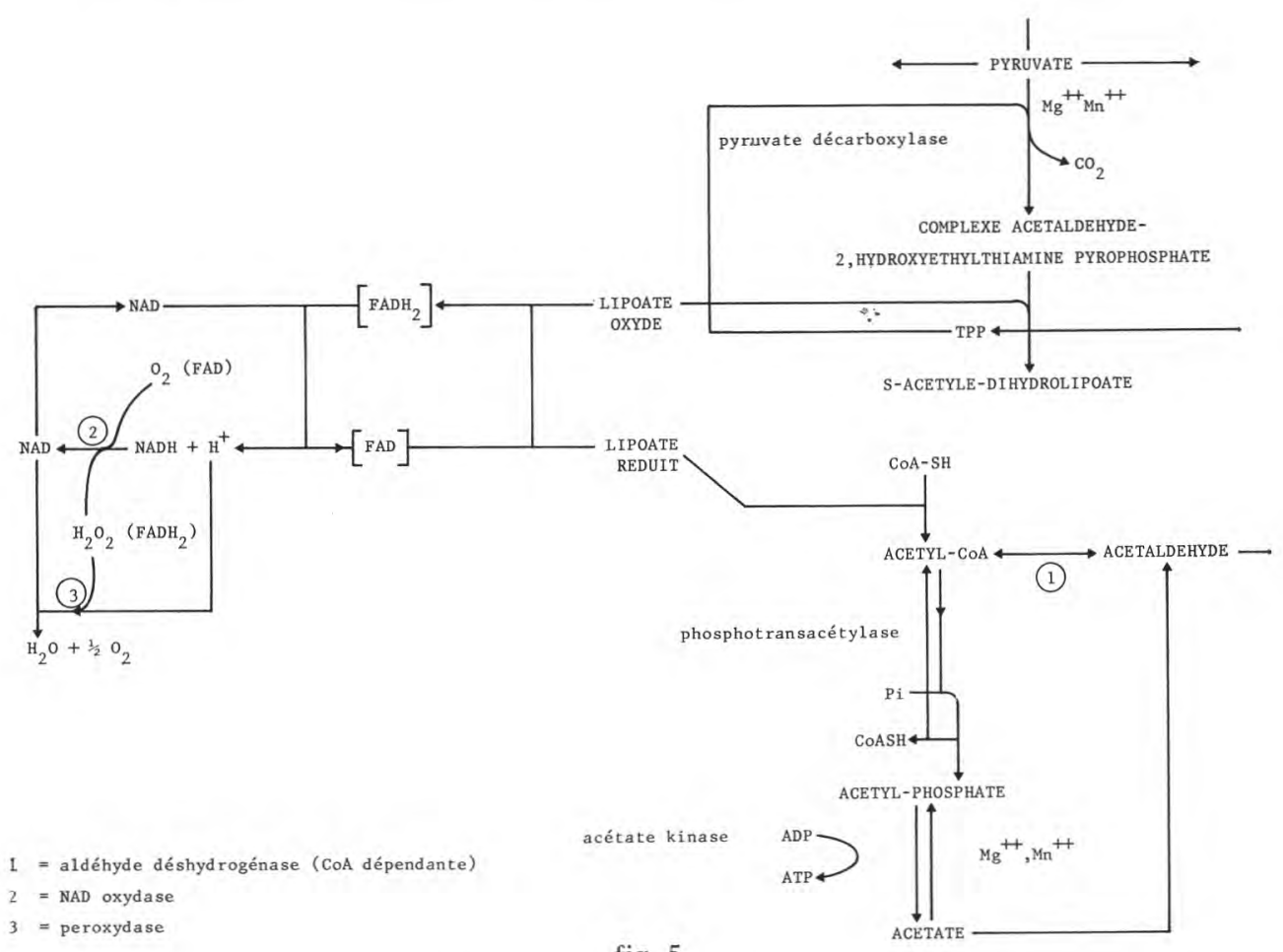

fig. 5

Utilisation du pyruvate chez les streptocoques du groupe $\mathrm{N}$ (voie partielle, se complète avec la figure 6) ; (selon THOMAs et al., 1979).

TPP $=$ thiamine pyrophosphate.

Pyruvate utilization in group $N$ streptococci (adapted from THомаs et al., 1979).

tes entre $\mathrm{pH}$ 6,5 et 5,5 en dépit de l'augmentation de la quantité de pyruvate utilisée aux $\mathrm{pH}$ les plus bas. Deux micro-moles d'acétate sont approximativement formées par micro-mole d'oxygène utilisée. Après saturation de la voie conduisant à l'acétate, les quantités d'acétoïne et de diacétyle formées augmentent lorsque le $\mathrm{pH}$ diminue. $\mathrm{A}$ des $\mathrm{pH}$ extérieurs inférieurs à 5,5 la production d'acétate semble inhibée tandis que la formation d'acétoïne et de diacétyle n'est inhibée qu'aux valeurs de $\mathrm{pH}$ inférieurs à 4,5 (Broome et al., 1980). Enfin, ces auteurs notent que la formation d'une mole d'acétate par les streptocoques du groupe $\mathrm{N}$ implique l'oxydation d'une mole de pyruvate et la production d'une mole de $\mathrm{CO}_{2}$, tandis que la formation d'une mole d'acétoïne ou de diacétyle requiert 2 moles de pyruvate et le dégagement de 2 moles de $\mathrm{CO}_{2}$. Comme les enzymes aldhéhyde déshydrogénase, phosphotransacétylase et acétate kinase sont pré- 
sentes chez les streptocoques du groupe $\mathrm{N}$, ces organismes sont capables de réduire l'acétyle co-enzyme A en acétaldéhyde. Ils contiennent aussi une alcool déshydrogénase NAD- dépendante qui réduit l'acétaldéhyde en éthanol. Chez Leuconostoc cremoris, on trouve aussi une alcool-déshydrogénase NAD- et NADP- dépendante (Lees et Jago, 1976).

Contrairement aux streptocoques du groupe $\mathrm{N}$, les cellules non proliférantes de $S$. thermophilus utiliseraient mieux le pyruvate à $\mathrm{pH} 7$ qu'aux $\mathrm{pH}$ inférieurs. D'autre part, il n'y a pas, dans cette espèce, un rapport stoechiométrique 1:1 entre la quantité de pyruvate utilisée et la quantité de $\mathrm{CO}_{2}$ libérée. La réaction globale impliquée serait du type : 2 pyruvate $\rightarrow \alpha$-acétolactate $+\mathrm{CO}_{2} \rightarrow$ acétoïne $+\mathrm{CO}_{2}$. S. thermophilus produirait plutôt peu d'acétoïne et accumulerait l'a-acétolactate (Tinson et al., 1982 b). Ces auteurs ont aussi montré que, contrairement aux streptocoques du groupe N, S. thermophilus produit très peu d'acétate à partir du pyruvate.

\section{IV.2. Utilisation des citrates}

On s'accorde généralement à penser que les bactéries lactiques produisent du diacétyle et de l'acétoïne pour éviter des concentrations trop élevées de pyruvate qui serait toxique (Collins, 1972). Or le pyruvate peut résulter de l'utilisation des citrates en présence d'une source d'énergie comme le lactose (Kempler et Mc Kay, 1981). Les concentrations élevées en pyruvate dépendent de la capacité de la bactérie à transporter le citrate dans la cellule puis à convertir celui-ci en pyruvate. Les voies du métabolisme du citrate ont été mises en évidence par Collins et ses collaborateurs aux Etats-Unis (voir en particulier les revues de Collins, 1972 et de Kempler et Mc Kay, 1981) et précisées récemment par Cogan (1981), Cogan et al. (1981) et Mellerick et Cogan (1981) (cf. fig. 6).

La première enzyme induite dans le métabolisme du citrate est la citrate perméase impliquée dans le transport de celui-ci vers l'intérieur de la cellule. Elle est fonctionnelle aux $\mathrm{pH}$ inférieurs à 6 ; son $\mathrm{pH}$ optimum étant 5 (Harvey et Collins, 1962). Une fois à l'intérieur de la cellule, le citrate est scindé en acétate et en oxaloacétate par la citrate-lyase (encore appelée citritase). Chez $S$. lactis subsp diacetylactis, cette enzyme est constitutive (Harvey et Collins, 1961 ; Cogan, 1981). Elle a été purifiée (Harvey et Collins, 1963 ; Singh et Srere, 1975 ; Kümmel et al., 1975). Son $\mathrm{pH}$ optimum est compris entre 7,4 et 7,6. La forme finale de la préparation purifiée de S. diacetylactis (Kümmel et al., 1975) contenait aussi une acétate : HS-citrate lyase ligase (qui est une enzyme acétylante convertissant la HS-citrate lyase inactive en une acétyle-S-citrate lyase active). Cette enzyme était aussi présente dans la préparation de citrate lyase partiellement purifiée obtenue à partir de Leuc. citrovorum (Kümmel et al., 1975). Chez Leuc. lactis, la citrate-lyase est, à la différence de celle obtenue 
chez $S$. diacetylactis, une enzyme totalement inductible par le citrate (Mellerick et Cogan, 1981). L'oxaloacétate est ensuite converti en pyruvate et $\mathrm{CO}_{2}$ par une oxaloacétate-décarboxylase. Dès 1961, Harvey et Collins caractérisaient les étapes suivantes conduisant à l'acétoïne lorsque les ions $\mathrm{Mg}^{++}$et $\mathrm{Mn}^{++}$et de la thiamine pyrophosphate (TPP) étaient présents (fig. 6). Les autres enzymes (acétolactatesynthase, diacétyle-réductase, acétoïne-réductase) sont constitutives chez S. lactis subsp diacetylactis (Cogan, 1981) ou partiellement induc-

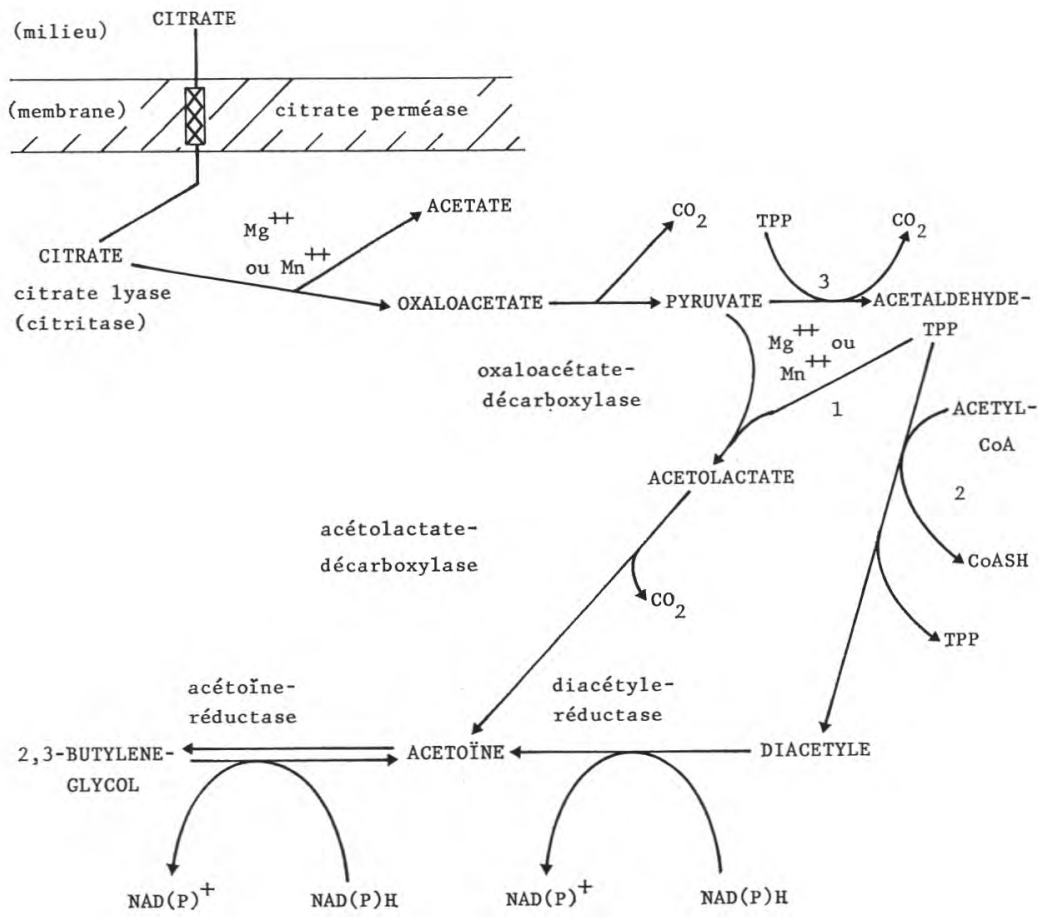

\footnotetext{
1 = acétolactate-synthase

2 = diacétyle-synthétase

3 = pyruvate-décarboxylase
}

fig. 6

Catabolisme du citrate par Streptococcus lactis subsp. diacetylactis (d'après Cogan, 1981 ; Kempler et Mc Kay, 1981).

$\mathrm{TPP}=$ thiamine pyrophosphate.

Citrate catabolism in Streptococcus lactis subsp. diacetylactis (adapted from Cogan, 1981 ; KeMpler and Mc Kay, 1981). 
tibles (acétolactate-synthase) chez Leuc. Lactis et d'autres bactéries lactiques hétérofermentaires (Mellerick et Cogan, 1981). Le co-enzyme A est le co-enzyme indispensable et il a été montré effectivement que de l'acétyl-co-enzyme A-1-14C était incorporé dans le diacétyle (Kempler et Mc Kay, 1981). La répression de la formation de la diacétyle réductase et de l'acétoïne réductase en présence de citrate peut expliquer pourquoi l'acétoïne s'accumule dans les cultures contenant des citrates. La régulation des quantités de NADH disponible indispensable pour ces enzymes intervient aussi pour moduler la formation du diacétyle et de l'acétoïne (Cogan, 1981).

En 1979, Kempler et Mc Kay ont démontré que le métabolisme du citrate est lié à un plasmide chez les streptocoques lactiques utilisant ce composé. Les souches S. lactis subsp diacetylactis 18-16 et DRC1 contiennent 6 familles distinctes de plasmides. Après traitement à l'acridine orange, on peut obtenir respectivement $2 \%$ et $0,5 \%$ de souches appartenant à un phénotype citrate-négatif ( Cit-). Ces $^{-}$. mutants ont aussi perdu un plasmide de 5,5 Mdal. Ils ont en fait perdu la faculté de transporter le citrate mais possèdent encore l'activité citritase. D'autre part, il existe des variants spontanés citrate négatif (souches WM4 11007 et DRC3) qui, eux non plus, ne possèdent pas le plasmide 5,5 Mdal (Kempler et Mc Kay, 1981). Enfin, parmi les 11 souches de $S$. lactis subsp diacetylactis étudiées par Chopin et Langella (1982), 10 possédaient un plasmide de 5,4 Mdaltons probablement identique au plasmide de 5,5 Mdaltons qui code pour la production d'une citrate perméase.

\section{NUTRITION AZOTEE}

\section{V.1. Exigences en acides aminés. Utilisation des acides aminés libres}

Les bactéries lactiques exigent la fourniture exogène d'acides aminés (Reiter et Oram, 1962) pour leur croissance car elles sont, pour la plupart, incapables d'en effectuer la synthèse à partir d'une source azotée plus simple. Law et al. (1976) précisent que, dans un milieu "synthétique ", les streptocoques du groupe $\mathrm{N}$ ont généralement besoin au moins de leucine, d'isoleucine, de valine, de méthionine, d'arginine, d'histidine, d'acide glutamique et, pour certaines souches, de phénylalanine, de proline et de cystine. Dans le lait, les concentrations en acides aminés libres sont trop faibles pour permettre aux levains lactiques de croître abondamment (Mills et Thomas, 1981 ; Thomas et Mills, 1981 ; Lawrence et al., 1976). Qui plus est, un des acides aminés essentiels (la méthionine) est absent sous forme libre dans le lait (Thomas et Mills, 1981). En utilisant des 
acides aminés marqués avec le ${ }^{14} \mathrm{C}$, Mills et Thomas (1981) ont effectivement montré que, pour $S$. cremoris $\mathrm{AM}_{2}$ et $\mathrm{E}_{8}$, ceux-ci étaient la source azotée la plus accessible dans le lait mais que le pool d'acides aminés libres constituait une source d'azote tout juste suffisante pour assurer la croissance à des basses densités cellulaires. Le système transportant la leucine et la glycine chez $S$. lactis, présente les propriétés d'un système perméase tel qu'il a été défini par Cohen et Monod (1957) puisque le transport de ces acides aminés exige une source d'énergie, dépend de la température, et peut être saturé. Le rapport entre la concentration interne et la concentration externe en glycine peut être de 30 et en leucine de 20 (Rice et al., 1978). Le fait que la glycine n'inhibe pas la prise de leucine suggère que ces deux acides aminés sont transportés par des systèmes différents. Il a été aussi montré que les acides aminés extracellulaires peuvent s'échanger avec le " pool » intracellulaire chez $S$. lactis (Rice et al., 1978). La réaction d'échange impliquant la glycine dépend de la présence de glucose. Cela avait été déjà décrit chez L. casei (Leach et Snell, 1960). Ce phénomène d'échange semble être un processus par lequel les acides aminés intracellulaires non essentiels peuvent être échangés contre des acides aminés extracellulaires essentiels (Rice et al., 1978). Chez $S$. thermophilus, les exigences en acides aminés pourraient être partiellement dépendantes de la présence du calcium dans le milieu (Reiter et Møller-Madsen, 1963). Elles portent essentiellement sur l'acide glutamique, l'histidine, la cystine, la méthionine, la valine, la leucine, le tryptophane ou la tyrosine. Si les besoins en acide glutamique et en histidine sont les pus importants quelles que soient les conditions de culture, il ne semble pas en être de même pour les autres acides aminés (cf. la revue d'Accolas et al., 1980). En fait, l'addition d'un seul acide aminé au lait a souvent peu d'effet tandis que les mélanges sont beaucoup plus efficaces (Accolas et al., 1971 ; Desmazeaud et Hermier, 1972 ; 1973) certains pouvant même être inhibiteurs (Desmazeaud et Hermier, 1973). Ainsi la valine n'est-elle indispensable qu'en présence d'isoleucine, la tyrosine qu'en présence d'un petit nombre d'acides aminés dans le milieu (Bracquart et Lorient, 1977 ; 1979 ; Bracquart et al., 1978). Les interférences entre acides aminés gênent considérablement l'interprétation des résultats (Payne et Tuffnel, 1980). Le transport des acides aminés à chaîne latérale branchée est un transport actif chez S. thermophilus (Akpemado et Bracquart, 1983). En effet, il n'a pas lieu sans une source d'énergie exogène comme le glucose. D'autre part, les inhibiteurs métaboliques de la glycolyse ou de l'utilisation de l'ATP sont aussi très actifs. Le transport est optimal entre 30 et $45^{\circ} \mathrm{C}$ et à $\mathrm{pH} 7,0$ pour les trois acides aminés (leucine, valine et iso-leucine). Un second pic existe à $\mathrm{pH} 5,0$ avec la valine et l'iso-leucine. Les constantes d'inhibition montrent que les trois acides aminés partagent au moins un système commun de transport. Enfin, deux systèmes de transport ont été décrits pour le glutamate et l'aspartate chez $S$. faecalis (Iaccarino et al., 1980), mais pas chez les autres bactéries lactiques. 


\section{V.2. Utilisation des peptides}

\section{V.2.1. UTILISATION DE LA FRACTION NON PROTÉIQUE DU LAIT (fraction NPN)}

Mills et Thomas (1981) ont montré que la fraction azotée de bas poids moléculaire du lait est une source importante d'azote pour les bactéries lactiques. En effet, l'hydrolyse acide de cette fraction NPN triple la concentration totale en acides aminés. Après obtention de lait marqué au ${ }^{14} \mathrm{C}$ (par injection d'acides aminés ${ }^{14} \mathrm{C}$ à une vache laitière) la fraction $\mathrm{NPN}-{ }^{14} \mathrm{C}$ était caractérisée par sa solubilité dans l'acide trichloracétique à $12 \%(\mathrm{p} / \mathrm{v})$ puis la plupart des peptides qu'elle contenait étaient obtenus après chromatographie sur Sephadex G 15 et utilisés comme source d'azote dans des milieux de culture. Ces expériences ont montré que la croissance des streptocoques du groupe $\mathrm{N}$ est supportée par des peptides dont le poids moléculaire est inférieur à 1500 daltons. Ceux-ci contiennent en particulier de la méthionine, le seul acide aminé essentiel qui soit absent du lait sous forme libre (Thomas et Mills, 1981).

\section{V.2.2. Utilisation ET TRANSPORT DES PEPTIDES EXOGÈNES}

La stimulation de la croissance par des peptides est connue depuis longtemps, en particulier chez Lactobacillus casei pour lequel une classe particulière de peptides-facteurs de croissance (strepogenin) avait été décrite (Sprince et Wooley, 1945 ; Merrifield et Wooley, 1958 ; Baudet et al., 1960).

Les streptocoques du groupe $\mathrm{N}$ sont capables d'utiliser des dipeptides pour leur croissance mais cette capacité varie très largement d'une souche à une autre, en particulier chez S. cremoris (Law, 1977). $S$. lactis utilise aussi les dipeptides mais aucune inhibition compétitive entre eux n'est observée, ce qui suggère que chaque dipeptide est transporté par un " porteur " spécifique ou hydrolysé auparavant (chaque acide aminé ou famille d'acides aminés étant alors transporté par des systèmes spécifiques) (Anraku, 1980 ; Law, 1977). S. cremoris possède un système de transport spécifique des tripeptides puisque ceux-ci n'inhibent pas de façon compétitive le transport des dipeptides (Law, 1978). La compétition pour la prise de glycyl $1{ }^{14} \mathrm{C}$-leucine, obtenue en présence de dipeptides contenant différents acides aminés, indiquerait que chez $S$. cremoris, il existe un système de transport commun à tous les dipeptides comme c'est le cas chez E. coli (Law, 1978). La croissance de $S$. cremoris avec des tri- et des tétrapeptides comme sources d'acides aminés et la compétition entre ces peptides, indiquent que cet organisme a en plus un système de transport spécialisé dans les oligopeptides (Law, 1978). Un tel système existe aussi chez S. lactis (Rice et al., 1978), ces auteurs ayant montré que le transport des peptides était à la fois énergie-dépendant et température-dépendant. La production d'acide peut être désaccouplée de la croissance par 
la présence de hautes concentrations salines dans le lait (Turner et Thomas, 1975). Cette inhibition de la croissance par $\mathrm{NaCl}$ serait due à l'inhibition des systèmes transportant les peptides et acides aminés à travers les enveloppes microbiennes.

De nombreux peptides stimulent la croissance et la production d'acide lactique de $S$. thermophilus cultivé dans le lait (Desmazeaud et Devoyod, 1970 ; Hemme et al., 1981 b). Après hydrolyse de la caséine entière par une protéase neutre et séparation des peptides en grandes classes de poids moléculaires par chromatographie, il a été montré que le groupe de peptides de poids moléculaire 1000-2 500 avait le plus grand pouvoir stimulant sur $S$. thermophilus souche 160 (Desmazeaud et Hermier, 1972). Après isolement et caractérisation de 14 peptides purs stimulants (de poids moléculaire moyen de 1500), on trouvait une grande variabilité dans leur composition. Seule la lysine était l'acide aminé commun à tous ces peptides. Ils fonctionneraient donc plutôt comme une source générale d'acides aminés (Desmazeaud et Hermier, 1972). D'autres peptides issus du glucagon auraient aussi le même rôle (Desmazeaud et Hermier, 1973). Par contre, en utilisant d'autres peptides issus du glucagon ou de synthèse, on a pu montrer que des peptides seraient pour $S$. thermophilus des sources préférentielles d'histidine (Desmazeaud et Hermier, 1973) ou d'acide glutamique, de méthionine et d'histidine (Bracquart et Lorient, 1979). Ainsi, l'effet stimulant global sur la production d'acide dans le lait obtenu avec un peptide est, chez $S$. thermophilus, plus bénéfique à la cellule que celui observé avec l'acide aminé fourni seul. Un cas analogue a été mis en évidence chez une souche de Lactobacillus delbrueckii, qui était incapable de concentrer l'histidine libre par suite de l'absence d'un système transporteur de l'acide aminé (Peters et al., 1953).

La " taille » supérieure limite pour le transport d'un peptide à travers les membranes chez les streptocoques du groupe $\mathrm{N}$ semble être de 5 à 6 résidus (Law et al., 1976 ; Law, 1978 ; Rice et al., 1978), ce qui implique que des peptides de la fraction NPN doivent être hydrolysés avant transport et leur utilisation intracellulaire pour la synthèse protéique (Mills et Thomas, 1981). Chez S. thermophilus, ce seuil existe aussi puisque l'action stimulante de peptides issus du glucagon diminue lorsque le nombre de résidus d'acides aminés passe de 5 à 12 ; certains dipeptides et tripeptides peuvent même exercer un effet inhibiteur (Desmazeaud et Hermier, 1973).

Enfin, chez les streptocoques du groupe $\mathrm{N}$, l'utilisation des tri et des dipeptides exige que le groupement $\mathrm{NH}_{2}$-terminal du peptide soit libre c'est-à-dire non substitué. Par contre, le groupement $\mathrm{COOH}$ terminal peut être substitué. D'autre part, il a été montré que $S$. cremoris ne peut pas transporter les peptides contenant un acide aminé de forme D puisque la D-Leucyl- Glycyl-Glycine n'inhibe pas de façon compétitive la prise de L-Leucyl-Glycyl-Glycine (Law, 1978). 


\section{V.3. Utilisation des protéines du lait}

Même si tous les acides aminés de la fraction NPN étaient utilisés par la cellule, les concentrations de certains seraient encore trop faibles pour assurer la croissance des bactéries lactiques telle qu'on l'observe dans du lait. Les niveaux d'arginine et de leucine de la fraction NPN ne représentent, par exemple, que $34 \%$ et $27 \%$ respectivement des concentrations minimums exigées pour que la croissance des streptocoques du groupe $\mathrm{N}$ atteigne une densité cellulaire suffisante pour provoquer la coagulation du lait (Thomas et Mills, 1981). L'utilisation des protéines du lait comme source azotée a été clairement démontrée par utilisation de protéines laitières marquées au ${ }^{14} \mathrm{C}$ (Mills et Thomas, 1981) dans un milieu à base de poudre de lait écrémé reconstituée (poudre de type "basse température "). Lorsque la culture se développe, l'activité spécifique ${ }^{14} \mathrm{C}$ incorporée dans les protéines bactériennes augmente aussi lorsqu'on atteint des densités cellulaires importantes. Cependant, il n'a pas pu être déterminé quelle était la protéine du lait la mieux utilisée (Mills et Thomas, 1981). $S$. cremoris semblerait même utiliser toutes les protéines du lait de la même manière. La caséine entière du lait est importante pour la nutrition azotée des bactéries lactiques, mais elle n'est pas suffisante car, comme l'indiquent Thomas et Mills (1981), dans les milieux à base de caséine, il faut toujours ajouter de l'extrait de levure apportant, entre autres choses, des acides aminés et peptides.

\section{V.4. Mécanismes d'utilisation des peptides et des protéines : activités protéolytiques des bactéries lactiques}

En raison de leur charge et de leur poids moléculaire, comme nous l'avons vu précédemment, les oligopeptides et, à plus forte raison, les protéines, ne peuvent traverser les enveloppes microbiennes, en particulier la membrane cytoplasmique. Donc pour être utilisés, ils doivent être au préalable hydrolysés par des systèmes protéolytiques soit extracellulaires, soit liés aux enveloppes. D'autre part, les plus courts peptides qui, eux, ont été transportés dans la cellule, doivent être hydrolysés en leurs acides aminés constitutifs par les enzymes protéolytiques intracellulaires (Law et Sharpe, 1978) (cf. fig. 7). Des publications ayant déjà passé en revue les équipements protéolytiques des bactéries lactiques (Lawrence et al., 1976 ; Castberg et Morris, 1976 ; Schmidt et al., 1976 ; Thomas et Mills, 1981), nous ne nous attacherons qu'à développer les données les plus récentes intéressant la spécificité d'action, la localisation cellulaire et les aspects génétiques.

V.4.1. TYPE D'ENZYMES PROTÉOLYTIQUES TROUVÉES CHEZ LES BACTÉRIES LACTIQUES ET LEUR LOCALISATION CELLULAIRE

\section{V.4.1.1. Problèmes méthodologiques}

La localisation cellulaire précise des enzymes protéolytiques chez les bactéries lactiques est rendue difficile en raison de la résistance au 


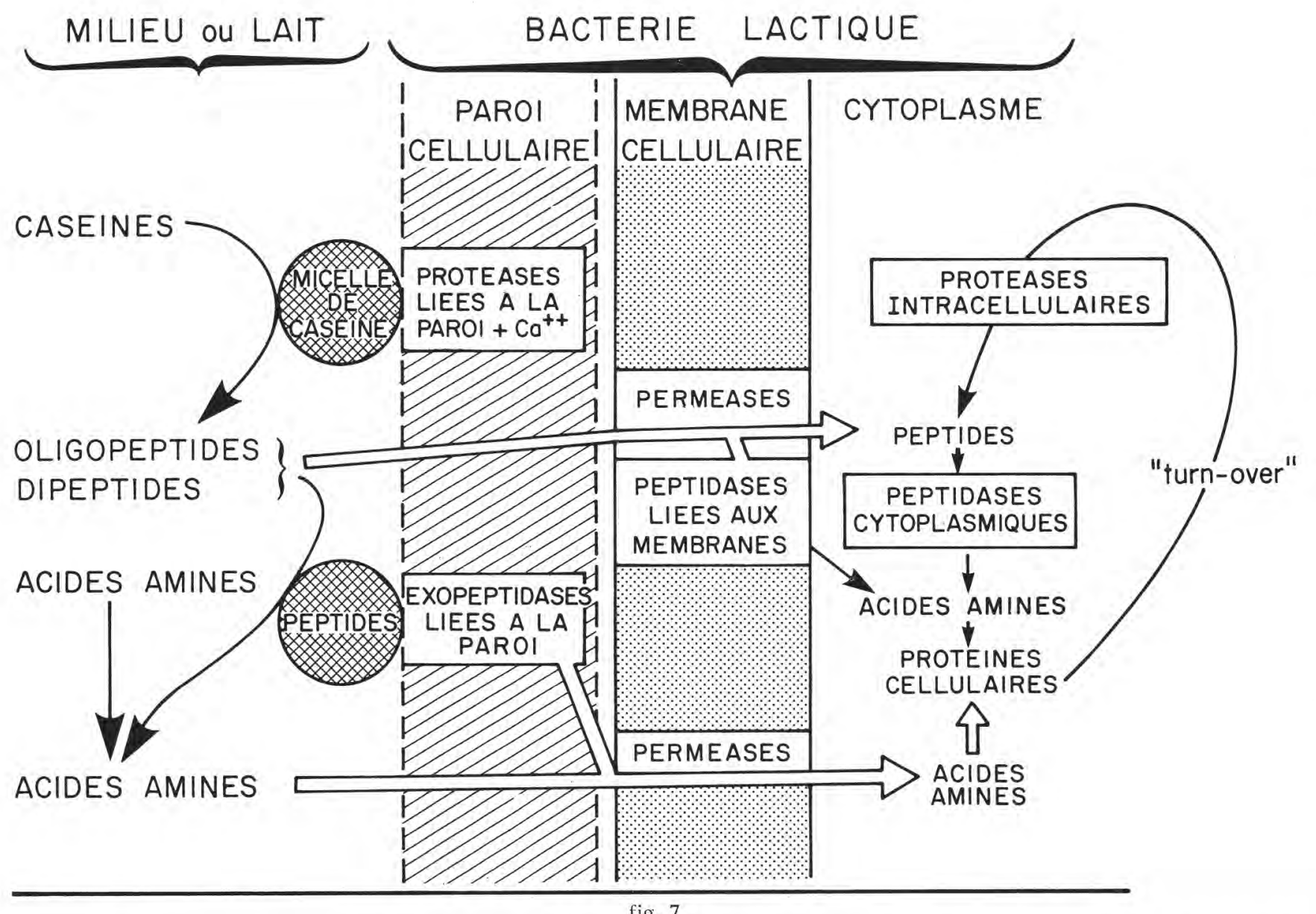

Utilisation des protéines, des peptides et des acides aminés par les bactéries lactiques (d'après ExTERKATE, 1976; LAW et SHARPE, 1978). $=>=$ système de transport $; \rightarrow=$ hydrolyse de la liaison peptidique.

Transport and utilization of proteins, peptides and aminoacids in lactic acid bacteria (adapted from EXTERKATE, 1976 ; LAW and SHARPE, 1978).

$=>=$ transport $; \rightarrow=$ peptide bond hydrolysis. 
lysozyme d'un certain nombre d'espèces et de la difficulté d'obtenir des surnageants qui, après formation des protoplastes, ne soient pas contaminées par des marqueurs protéiques intracellulaires tels que l'aldolase et la lactate-déshydrogénase. Cependant, des lyses par le lysozyme ont été obtenues aussi bien chez les streptocoques du groupe N (Law, 1979) que chez certains lactobacilles thermophiles tels que $L$. helveticus (Vescovo et Bottazzi, 1979). Une autre technique consiste à produire une enzyme lytique associée à un phage, à condition que la préparation lytique active ne contienne pas d'activité protéolytique parasite. Des localisations précises d'enzymes ont ainsi pu être faites chez S. Lactis (Thomas et al., 1974) ou chez Lactobacillus casei (E1 Soda et al., 1978 a).

Le deuxième problème méthodologique qui s'est posé, a porté sur la nature du substrat, en particulier pour les endopeptidases. En effet, si la caséine entière est intéressante pour mettre en évidence des activités protéolytiques globales, les méthodes traditionnelles dosant les peptides libérés dans l'acide trichloracétique ne sont pas toujours suffisamment sensibles pour appréhender les activités extracellulaires ou liées aux cellules (Thomas et Mils, 1981). Aussi, le marquage isotopique des caséines peut-il augmenter considérablement la sensibilité des méthodes. Quoique utilisé, le marquage à l'iode 125 (Desmazeaud et Jugé, 1976) est moins intéressant que celui avec le formaldéhyde ${ }^{14} \mathrm{C}$ (Exterkate, 1975). Cependant, des modifications chimiques, plus ou moins profondes, du substrat, résultant de ces traitements, sont à craindre car elles peuvent entrainer une libération, dans les filtrats trichloracétiques, de produit radioactif non lié à une activité protéolytique.

Enfin, les exopeptidases ont été bien caractérisées grâce à de nombreux substrats synthétiques : acides aminés monosubstitués (de type acide aminé-p-nitroanilide ou $\beta$-naphtylamide), dipeptides (monosubstitué ou non), tripeptides, etc. (Desmazeaud et Jugé, 1976).

\section{V.4.1.2. Protéinases et peptidases extracellulaires ou liées aux enveloppes cellulaires}

Les streptocoques lactiques du groupe $\mathrm{N}$ possèdent des protéinases liées aux parois capables de dégrader les protéines (Thomas et al., 1974 ; Exterkate, 1975 et 1976 b) ; certaines souches de S. cremoris possèdent même trois protéinases, deux d'entre elles étant de type acide et la troisième de type neutre (Exterkate, 1976 b). Cependant, la liaison de certaines de ces enzymes avec la paroi est si faible qu'elles peuvent être libérées dans le milieu par exemple en maintenant les cellules à $25^{\circ} \mathrm{C}$ en l'absence d'ions $\mathrm{Ca}^{++}$(Thomas et Mills, 1981). La libération de ces protéinases augmente avec l'élévation de température (de 0 à $34^{\circ} \mathrm{C}$ ) et celle du $\mathrm{pH}($ de 5,5 à 8,7 ), l'inactivation apparaissant à $34^{\circ} \mathrm{C}$ et à $\mathrm{pH} 8,7$. Avec des cellules suspendues dans du tampon, la libération des protéinases cesse par addition de chlorure de calcium ou en descendant la température 
à $0^{\circ} \mathrm{C}$, ou encore en abaissant le $\mathrm{pH}$ à 5,5 . Le chlorure de sodium et le saccharose évitent partiellement cette libération (Mills et Thomas, 1978). Ces faits permettent de penser que c'est la perméabilité de la paroi qui est modifiée, les ions calcium pouvant être directement impliqués dans la liaison de la protéinase à la paroi. Dans le lait, la présence des ions calcium et la diminution du $\mathrm{pH}$ au cours de la croissance des bactéries lactiques sont avantageuses pour les germes puisqu'elles retiennent les protéinases et, ce faisant, permettent que les produits de la protéolyse soient libérés au niveau des cellules et tout de suite transportés à l'intérieur de celles-ci ou directement transformés en acides aminés libres par les exopeptidases liées aux enveloppes cellulaires (Mills et Thomas, 1978). Lactobacillus bulgaricus possède une protéinase liée fortement aux enveloppes, dont la localisation précise n'a pas été effectuée. Les conditions optimales de son activité sont $45-50^{\circ} \mathrm{C}$ et $\mathrm{pH} 5,2-5,8$. Elle est inhibée par les agents chélateurs (Argyle et al., 1976). Cette enzyme est surtout active sur la caséine $\beta$ et son activité sur les protéines du sérum est faible (Chandan et al., 1982).

Des exopeptidases pourraient être extracellulaires puisqu'une dipeptidase a été retrouvée dans des surnageants de culture de $S$. lactis et de S. cremoris. Ces activités étaient inhibées par les chélateurs (EDTA) et réactivées par les ions $\mathrm{Co}^{++}, \mathrm{Mn}^{++}$et $\mathrm{Zn}^{++}$. Les poids moléculaires de ces enzymes étaient respectivement de 25000 et 28000 (Law, 1979).

Cependant, ce sont les exopeptidases liées aux enveloppes qui ont été le plus souvent mises en évidence. En effet, S. cremoris, qui utilise les peptides, possède une dipeptidase qui est sensible au mercapto-éthanol, activée par les ions $\mathrm{Mg}^{++}$et qui peut être libérée par le lysozyme. S. lactis posséderait aussi une dipeptidase et une tripeptidase liées aux parois cellulaires (Law, 1979). Ces peptidases seraient sensibles à l'EDTA et au mercapto-éthanol et seraient réactivées par les ions $\mathrm{Mg}^{++}$. Par contre, chez S. cremoris HP, l'aminopeptidase et la proline-iminopeptidase ne sont pas libérées par le lysozyme (Exterkate, 1975). Elles restent associées à une fraction particulaire de la membrane. D'autre part, cette souche possède aussi une pyrrolidone-carboxylpeptidase membranaire (Exterkate, 1977) lui permettant d'utiliser éventuellement les peptides dont le résidu $\mathrm{NH}_{2^{-}}$ terminal présente cette structure (c'est le cas du résidu $\mathrm{NH}_{2}$-terminal de la caséine kappa, Mercier et al., 1973). En étudiant l'effet de solvants tels que le n-butanol, Exterkate (1977) a montré que l'état physique et l'organisation des composants lipidiques de la membrane déterminaient l'efficacité catalytique de l'enzyme. Les changements induits par la température dépendaient de la phase de croissance à laquelle les cellules étaient récoltées. Enfin, il semblerait que chez S. cremoris HP, la pyrrolidone carboxylylpeptidase soit localisée (avec la protéase active à $50^{\circ} \mathrm{C}$ dite $\mathrm{P} 50$ ) à l'intérieur de la membrane et liée fortement aux lipides (constituant ainsi une entité fonctionnelle 
lipoprotéique) alors que l'aminopeptidase, la proline-imino-peptidase et la protéase active à $37^{\circ} \mathrm{C}$, dite $\mathrm{P} 37$, ne seraient pas localisées à l'intérieur de la membrane (Exterkate, 1979 et 1981). Ainsi, ces différentes enzymes protéolytiques agiraient de façon synergique en occupant des positions variées, la dégradation des peptides se faisant non seulement avant la traversée de la couche lipidique de la membrane, mais aussi au cours de ce transport. Ceci est en accord avec les mécanismes généraux de l'utilisation des nutriments azotés décrits chez les bactéries (Payne, 1976). Enfin, chez Lactobacillus lactis, une aminopeptidase liée à la surface cellulaire peut être libérée par action du lysozyme. Après purification, il a été montré que cette enzyme présentait un optimum de température à $47,5^{\circ} \mathrm{C}$ et un $\mathrm{pH}$ optimum de 6,2 à 7,2. Elle était activée par les ions $\mathrm{Co}^{++}$et $\mathrm{Zn}^{++}$et inhibée par les chélateurs et les ions $\mathrm{Fe}^{+++}, \mathrm{Cu}^{++}$ou $\mathrm{Hg}^{++}$(Eggimann et Bachmann, 1980).

\section{V.4.1.3. Protéinases et peptidases intracellulaires}

Les bactéries lactiques possédent aussi un équipement protéolytique intracellulaire important. En effet, en plus de leur rôle strictement nutritionnel qui permet aux bactéries d'utiliser les peptides ayant franchi les enveloppes microbiennes, les enzymes protéolytiques intracellulaires interviennent dans la nutrition à trois autres niveaux : lors de l'hydrolyse de peptides éventuellement toxiques, dans le "turn-over " des protéines intracellulaires et dans la synthèse des protéines microbiennes (Holzer et al., 1975), comme il est indiqué sur la figure 7 .

II se pose, pour ces enzymes, les mêmes problèmes méthodologique de localisation cellulaire que ceux évoqués à propos des peptidases extracellulaires ou liées aux enveloppes. En effet, beaucoup d'auteurs ont utilisé des systèmes de broyage suffisamment violents, capables de décrocher les enzymes des parois ou des membranes et de les faire passer dans la fraction appelée "soluble » ou cytoplasmique. Inversement, on peut aussi craindre que des enzymes véritablement " solubles " dans le cytoplasme s'adsorbent sur des fractions particulaires en raison de traitements trop drastiques (Exterkate, 1975).

Ces réserves étant faites, on a observé que $S$. cremoris HP (dans les lysats de sphéroplastes) montre une activité protéolytique dite $\mathrm{Pi}$, sur la caséine, à $37^{\circ} \mathrm{C}$ (mais non à $50^{\circ} \mathrm{C}$ ), qui est différente des activités protéolytiques liées aux enveloppes, P 37 et P 50 (Exterkate, 1975). Après broyage des cellules, S. lactis montre aussi une activité protéolytique faible dans la fraction «soluble " si les cellules sont cultivées à bas $\mathrm{pH}$. Aucune activité protéolytique n'est détectée dans la fraction ribosomale (Schmidt et al., 1977 a), Chez S. diacetylactis, une métalloprotéase a été purifiée et sa spécificité d'action déterminée. Après inhibition par les chélateurs, elle était réactivée par les ions $\mathrm{Co}^{++}$ou $\mathrm{Mn}^{++}$. Une enzyme de ce type a aussi été retrouvée chez $S$. cremoris mais elle était réactivée par les ions $\mathrm{Ca}^{++}$(Ohmiya 
et Sato, 1975). Elle attaque rapidement des chaînes peptidiques comme l'insuline et le glucagon mais hydrolyse peu ou n'hydrolyse pas les protéines natives. Sa spécificité correspond à celle des métalloprotéinases microbiennes (EC 3.4.24.4) (Desmazeaud et Zévaco, 1976). Son action sur la caséine $\beta$ est faible, mais elle agit de façon beaucoup plus profonde sur des peptides issus de la caséine $\beta$ après attaque de la présure (Zévaco et Desmazeaud, 1980). Ce type de métalloprotéinase a été également retrouvé chez $S$. thermophilus qui possède une enzyme plus active sur l'insuline ou le glucagon que sur les caséines (Desmazeaud, 1974). Ces enzymes (Desmazeaud et Zévaco, 1976) ont des spécificités d'action différentes de celles des protéases intracellulaires étudiées chez S. lactis (Cowman et al., 1968 ; Westhoff et Cowman, 1971) ou chez les streptocoques du groupe A (Gerwin et al., 1966). D'autre part, S. durans possède une protéase intracellulaire à groupes sulfhydryles, puisque le p-chloromercuribenzoate l'inhibe comme la N-éthylmaléimide ou l'iodoacétamide. Elle est particulièrement thermorésistante puisqu'un chauffage à $97-99^{\circ} \mathrm{C}$ pendant 60 min à pH 6 et 7,5 ne l'inhibe pas (Wallace et Harmon, 1970).

Chez Lactobacillus helveticus, les localisations cellulaires précises n'ont pas montré l'existence de protéinase intracellulaire (Vescovo et Bottazzi, 1979). Chez L. casei, il existe une endopeptidase très spécifique hydrolysant les substrats de la chymotrypsine (du type de la succinyl-L-phénylalanine-p-nitroanilide). Cette enzyme serait liée aux ribosomes car elle est retrouvée dans la fraction obtenue après centrifugation à $150000 \mathrm{~g}$ correspondant aux ribosomes (E1 Soda etal., 1978 a). Cependant, son rôle physiologique n'a pas pu être déterminé car, après purification, l'étude de sa spécificité a montré que cette enzyme ne pouvait pas attaquer les caséines ni les peptides issus des caséines ni différents peptides de synthèse (El Soda et Desmazeaud, 1981).

De très nombreuses publications ont décrit des activités exopeptidasiques intracellulaires chez les bactéries lactiques (Thomas et Mills, 1981). Grâce à la méthode électrophorétique préconisée par Sørhaug et Solberg (1973) chez S. lactis, le fractionnement des aminopeptidases, dipeptidases ou tripeptidases a pu être réalisé et la spécificité de ces enzymes caractérisée par leur activité sur de nombreux peptides de synthèse ou dérivés d'acides aminés. Chez $S$. lactis et $S$. cremoris, une aminopeptidase, une tripeptidase et deux dipeptidases intracellulaires ont été décrites. Ce sont des métalloenzymes, inhibées par les chélateurs (EDTA) et réactivées par les ions $\mathrm{Co}^{++}, \mathrm{Mn}^{++}$, $\mathrm{Zn}^{++}$. Leur poids moléculaire était respectivement de 49000,34000 et 25000 (Law, 1979). L'activité dipeptidasique soluble a un $\mathrm{pH}$ optimum voisin de 8 , comme la dipeptidase retrouvée dans la fraction ribosomale. En général, chez $S$. lactis, les peptides de type leucyleou alanyle- sont de bons substrats (Schmidt et al., 1977 a). D'autre part, les streptocoques du groupe $\mathrm{N}$ sont capables d'hydrolyser les peptides contenant de la proline puisqu'ils possèdent une proline- 
iminopeptidase, une proline-iminodipeptidase et une aminopeptidase$\mathrm{P}$ (Mou et al., 1975). Ce fait est d'autant plus intéressant pour leur nutrition que les caséines renferment de nombreux résidus prolyles, acide aminé essentiel pour $S$. cremoris (Reiter et Oram, 1962). Chez S. diacetylactis, une dipeptidase a été purifiée. Son $\mathrm{pH}$ optimum est 7,5-8 et elle est stable jusqu'à $50^{\circ} \mathrm{C}$ de $\mathrm{pH} 7$ à $\mathrm{pH}$ 8. Son activité est inhibée par les chélateurs (EDTA) et elle est réactivée par les ions $\mathrm{Co}^{++}$et $\mathrm{Zn}^{++}$. Elle hydrolyse préférentiellement les dipeptides présentant un résidu méthionyle $\mathrm{NH}_{2}$-terminal (Met-Ala $>$ Met-Val $>$ Met-Ile) (Desmazeaud et Zévaco, 1977). Cette espèce possède aussi deux autres aminopeptidases intracellulaires, métalloenzymes réactivables par les ions $\mathrm{Co}^{++}, \mathrm{Mn}^{++}$ou $\mathrm{Mg}^{++}$. L'aminopeptidase I présente une large spécificité et hydrolyse les tripeptides (de type Phe-Leu-Leu ou MetLeu-Gly) et les dérivés d'acides aminés-p-nitroanilide ou $\beta$-naphtylamide. L'aminopeptidase II n'hydrolyse que certains tripeptides. Leur optimum d'action est respectivement de 6,5 et de 7 et leur tempéra$\mathrm{pH}$ optimum d'action est respectivement de 6,5 et de 7 et leur température optimum de $35^{\circ} \mathrm{C}$. Elles sont thermosensibles et dénaturées à $45^{\circ} \mathrm{C}$ (Desmazeaud et Zévaco, 1979).

Toutes les souches de $S$. thermophilus possèdent une aminopeptidase de type leucine-aminopeptidase (Bouillanne et Desmazeaud, 1980). Certaines souches ont aussi une seconde aminopeptidase de type arginine-aminopeptidase (EC 3.4.11.6) généralement inactive sur les dipeptides. Toutes les souches montrent d'autre part, une prolyledipeptidase non spécifique capable d'hydrolyser de nombreux dipeptides (Desmazeaud et Jugé, 1976). Une aminopeptidase et une dipeptidase intracellulaires ont été purifiées et caractérisées. Ce sont aussi des métalloenzymes réactivées par les ions $\mathrm{Co}^{++}$et $\mathrm{Mn}^{++}$. $\mathrm{La}$ dipeptidase présente une spécificité envers les dipeptides ayant un résidu $\mathrm{NH}_{2}$-terminal hydrophobe et volumineux. L'aminopeptidase est de large spécificité quoiqu'elle n'hydrolyse pas les dipeptides ayant un résidu $\mathrm{NH}_{2}$-terminal glycyle ou histidyle ou ceux contenant un résidu prolyle ou phénylalanyle (Rabier et Desmazeaud, 1973).

Des activités exopeptidasiques intracellulaires ont été caractérisées après séparation électrophorétique chez tous les lactobacilles. $L$. helveticus et $L$. bulgaricus possèdent une dipeptidase et une aminopeptidase, alors que $L$. acidophilus contient une aminopeptidase et deux activités dipeptidasiques (El Soda et Desmazeaud, 1982). Chez les lactobacilles hétérofermentaires, ce sont les souches de L. brevis qui possédent l'équipement le plus riche en dipeptidases (El Soda et al., 1982). Quant à Lactobacillus plantarum, il se distingue de $L$. casei par son équipement en exopeptidases intracellulaires (El Soda et al., 1983). Cette dernière espèce possède même une carboxypeptidase spécifique capable de libérer l'arginine située dans des peptides en position $\mathrm{COOH}$-terminale. Ce type d'enzyme très rarement trouvé chez les bactéries, a été séparé (à partir de la fraction soluble d'un broyat cellulaire) d'une aminopeptidase et d'une dipeptidase par chromatographie d'affinité. Ces trois enzymes sont aussi des métal- 
loenzymes réactivables par les ions $\mathrm{Co}^{++}$et $\mathrm{Mn}^{++}$(El Soda et al., 1978 b). Dans toutes ces études, les spécificités des exopeptidases ont été déterminées en utilisant de nombreux peptides ou dérivés d'acides aminés de synthèse.

\section{V.4.2. Facteurs modulant L'activité PROtÉOlytique}

\section{V.4.2.1. Facteurs physiologiques.}

Chez $S$. cremoris, le milieu de croissance peut modifier le niveau de l'activité protéolytique des cellules. On peut s'attendre à un effet sur la synthèse des enzymes ou, une fois celles-ci synthétisées, sur leur stabilité, ou encore à un effet résultant d'une modification de la population bactérienne, favorisant par exemple le développement d'un variant lent ou au contraire celui d'un variant rapide (Exterkate, 1976 a). Quoique le problème de l'induction éventuelle des activités protéolytiques ne soit pas résolu, il a été observé que, chez S. lactis, la synthèse de la protéinase "membranaire " est stimulée par les acides aminés et réprimée par des hydrolysats de caséine (Westhoff et Cowman, 1970). Chez Lactobacillus casei se développant dans un milieu chimiquement défini, on a pu observer que les activités spécifiques de la dipeptidase, de la carboxypeptidase et de l'activité caséinolytique globale n'étaient que peu influencées par la nature de la source azotée alors que les activités spécifiques de l'aminopeptidase et d'une endopeptidase étaient fortement augmentées lorsque la source azotée était un mélange d'acides aminés (El Soda et al., 1978 a.)

Le stade physiologique de croissance affecte aussi le niveau des activités protéolytiques. Chez certains streptocoques du groupe $\mathrm{N}$, ce sont surtout les activités de la protéinase «soluble» et de la dipeptidase associée aux ribosomes qui chutent lorsque le temps d'incubation est prolongé (Schmidt et al., 1977 b). Chez L. casei, un effet analogue peut être observé surtout pour les activités aminopeptidase et carboxypeptidase (E1 Soda et al., 1978 a). Chez les lactobacilles thermophiles, la température de croissance est un facteur contrôlant les activités exopeptidasiques intracellulaires. De même, le pH externe intervient chez ces bactéries pour réguler les activités spécifiques qui diminuent lorsque le $\mathrm{pH}$ du milieu est fortement abaissé (Ezzat et al., 1982).

\section{V.4.2.2. Facteurs génétiques}

Il a été montré que, dans des cultures de $S$. lactis coagulant rapidement le lait, il existe des clones qui, issus de colonies isolées sur milieu gélosé convenable, donnent des cultures qui n'acidifient et ne coagulent le lait que lentement (Lawrence et al., 1976). Depuis, il a été trouvé, par exemple chez $S$. cremoris, que ces "variants lents » ne possédent pas les protéases PI et PII associées aux parois (Exterkate, 1976 a). Par contre, ces variants " coagulant lentement le lait » possédent tout de même des activités peptidasiques et des systèmes 
de transport de peptides identiques à ceux de la souche parentale (Thomas et Mills, 1981). Ces variants ne sont plus capables d'utiliser les protéines du lait et ne peuvent plus se développer qu'aux dépens des acides aminés et des peptides du lait, ce qui ne leur permet d'atteindre que 10 à $25 \%$ des densités cellulaires normalement atteintes par les souches parentales. Dans certains cas, la production d'acide se poursuit lentement en l'absence de toute croissance, la coagulation du lait finissant donc par se produire (Lawrence et al., 1976). Des variants qui coagulent lentement le lait peuvent également être isolés en induisant des pertes de plasmides présents chez le type sauvage comme cela a été fait chez S. lactis (Pearce et al., 1974). De telles souches (désignées prt- c'est-à-dire protéase négative) ont effectivement perdu aussi l'activité protéolytique liée à la surface cellulaire. Parmi les mutants spontanés, il a également été aussi mis en évidence qu'une perte de l'activité protéolytique de surface correspondait à la perte d'un plasmide dont la taille moléculaire était de $10^{7}$ (Mc Kay et Baldwin, 1975). Cependant, chez d'autres souches de $S$. lactis et de $S$. lactis subsp diacetylactis ou chez $S$. cremoris, une telle démonstration n'a pu être obtenue sans une certaine ambiguïté (Davies et Gasson, 1981). La perte simultanée de la fermentation du lactose et de l'activité protéinasique suggérait en effet que ces caractères étaient liés et pouvaient résider sur le même plasmide (Kuhl et al., 1979). Cependant, la nature exacte de cette relation n'est pas claire car, bien que les deux activités soient transférées ensemble pendant la transduction, elles apparaissent distinctes lors de la conjugaison (Davies et Gasson, 1981).

\section{EXIGENCES VITAMINIQUES}

Les streptocoques du groupe $\mathrm{N}$ exigent un certain nombre de vitamines, en particulier la niacine et l'acide pantothénique (Reiter et Oram, 1962). La vitamine B6 (pyridoxal) est stimulante ; l'acide aminé L-alanine peut remplacer cette dernière chez certaines souches. En général, l'acide folique ou folinique, la thiamine et la vitamine B12 ne sont pas exigés. Il existe une distinction claire entre $S$. lactis et $S$. cremoris, cette dernière espèce exigeant la riboflavine. Les exigences en biotine ont été plus difficiles à mettre en évidence car des interférences avec l'utilisation du $\mathrm{CO}_{2}$ peuvent se produire. En effet, le $\mathrm{CO}_{2}$ serait essentiel pour la croissance des streptocoques lactiques car il serait impliqué dans la biosynthèse de l'acide aspartique et des acides gras par un phénomène de fixation faisant intervenir la biotine (Law et Sharpe, 1978).

Les streptocoques thermophiles montrent une exigence absolue en acide pantothénique et en riboflavine et à un moindre degré en thiamine, en nicotinamide (ou acide nicotinique) et en biotine. La 
pyridoxine (ou ses dérivés) stimule fortement leur croissance (Guss et Delwiche, 1954).

Les besoins vitaminiques des lactobaciles ont été rassemblés dans le tableau 1. Toutes les espèces ont un besoin absolu en pantothénate de calcium et en niacine et des exigences différentes pour les autres vitamines. Les concentrations de (et les équilibres en) vitamines du lait peuvent, pour certaines souches (et en particulier pour les lactobacilles) se trouver insuffisantes, ce qui expliquerait l'effet stimulant généralement observé lorsqu'on ajoute de l'extrait de levure au lait. Il a été aussi montré que $L$. bulgaricus exigeait du $\mathrm{CO}_{2}$ pour une croissance optimum dans le lait. Cependant, aucun mécanisme explicatif n'a été proposé (Driessen et al., 1982). En conclusion, le lait contient toutes les vitamines exigées par les bactéries lactiques, en général en concentration suffisante. Cependant, des fluctuations de la concentration en vitamines peuvent se produire selon la saison, le stade de lactation, etc., ce qui peut affecter la vitesse de croissance des levains C. Reiter et Møller-Madsen, 1963).

\section{INFLUENCE DES BASES AZOTEES, DES MINERAUX ET DES ACIDES GRAS}

La production d'acide dans le lait par S. lactis C 10, peut être stimulée par le mélange adénine, guanine, uracile et xanthine (Selby Smith et al., 1975). S. thermophilus présente quant à lui, une exigence absolue pour ces quatre bases dans un milieu "semi-synthétique " (Ramasamy et Natarajan, 1981). D'autres souches de S. lactis et Lactobacillus casei peuvent être aussi stimulées par le mélange hypoxanthine + adénine (Zielke et al., 1978). Chez S. lactis C 10, le glucose stimule fortement la prise d'adénine mais n'a aucun effet sur celle de la guanine (Hillier et al., 1978). Ces auteurs supposent que les streptocoques du groupe $\mathrm{N}$ peuvent transformer l'adénine suivant la voie suivante :

Adénine $\rightarrow$ hypoxanthine $\rightarrow$ inosine-monophosphate $\rightarrow$ guanosinemonophosphate. Dans les milieux synthétiques, les lactobacilles exigent la présence d'adénine, de cytidine, de desoxyguanosine, de guanine, de thymidine et d'uracile à une concentration de $0,05 \mathrm{~g} / 1$ (Ledesma et al., 1977). La dégradation de la thymidine a été mise en évidence chez $L$. acidophilus. En plus d'une trans-N-glycosidase, cette espèce possède une thymidine phosphorylase (ou thymidine hydrolase) capable de libérer de la thymine (Sawula et al., 1974).

Mis à part les rapports sur le rôle précis des cations dans la résistance à l'oxygène ou dans les différentes réactions métaboliques, peu d'études ont été consacrées au rôle global des métaux dans la nutrition des bactéries lactiques. Il a été montré cependant que les ions $\mathrm{Fe}^{3+}, \mathrm{Mg}^{2+}, \mathrm{Mo}^{4+}$ et $\mathrm{Se}^{4+}$ pouvaient intervenir dans la nutrition des 
TABLEAU 1 - TABLE 1

Exigences vitaminiques des lactobacilles (RogosA, 1974)

\begin{tabular}{|c|c|c|c|c|c|c|c|}
\hline & L. lactis & $\begin{array}{l}\text { L. bulga- } \\
\text { ricus }\end{array}$ & $\begin{array}{l}\text { L. helve- } \\
\text { ticus }\end{array}$ & $\begin{array}{l}\text { L. acido- } \\
\text { philus }\end{array}$ & L. casei & $\begin{array}{l}\text { L. planta- } \\
\text { rum }\end{array}$ & L. brevis \\
\hline Calcium pantothénate & ++ & ++ & ++ & ++ & ++ & ++ & ++ \\
\hline Niacine & ++ & ++ & ++ & ++ & ++ & ++ & ++ \\
\hline Riboflavine & ++ & ++ & ++ & ++ & ++ & \pm & - \\
\hline Vitamine B 12 (cyanocobalamines) & \pm & \pm & - & \pm & - & - & - \\
\hline Thiamine & - & - & - & - & - & - & ++ \\
\hline Pyridoxal ou pyridoxamine & - & - & ++ & - & + & - & - \\
\hline Acide folique & - & - & - & ++ & ++ & - & ++ \\
\hline Thymidine & - & - & - & - & - & - & n.d. \\
\hline \multicolumn{8}{|c|}{$\begin{array}{rr}++: \text { vitamine exigée. } & - \text { : vitamine non exigée. } \\
+ \text { + vitamine parfois exigée, ou stimulante. } & \text { n.d. : exigence non déterminée. } \\
\text { I: vitamine exigée chez quelques souches seulement. } & \end{array}$} \\
\hline
\end{tabular}


streptocoques mésophiles (Reiter et Moller-Madsen, 1963 ; Law, 1982) et les ions $\mathrm{Mg}^{2+}$ et $\mathrm{Mn}^{2+}$ (De Man et al., 1960) et $\mathrm{Fe}^{2+}$ (Ledesma et al., 1974) dans la nutrition des lactobacilles.

Chez L. plantarum, les ions $\mathrm{Mn}^{2+}$ trouvés en fortes concentrations sont associés à des polyphosphates de haut poids moléculaire, ce qui interviendrait comme système de régulation dans leur rôle favorisant la résistance de la bactérie à l'oxygène (Archibald et Fridovich, 1982). Dans certains milieux industriels (par exemple sur mélasses) il a été montré que le sulfate de thorium ou le sulfate de zirconium pouvait stimuler la croissance de L. bulgaricus (Tiwari et al., 1980). L'addition des ions $\mathrm{Cu}^{2+}$ à une concentration $\leqslant 8 \mathrm{mg} / 1$ n'aurait aucun effet sur la croissance des levains. Il faudrait atteindre $120 \mathrm{mg} / \mathrm{l}$ pour observer une inhibition marquée (Gudkov et al., 1982). Ces auteurs ont montré aussi qu'une souche de Leuconostoc pouvait être stimulée en présence des ions $\mathrm{Fe}^{3+}$ à une concentration comprise entre 10 et $100 \mathrm{mg} / \mathrm{l}$. D'autre part, il semblerait aussi que le cuivre puisse avoir un effet sur la morphologie des bactéries lactiques cultivant dans le lait (Kolodkin, 1979).

Enfin, bien que les bactéries lactiques présentent un certain pouvoir lipolytique (faible, il est vrai) (Stadhouders et Veringa, 1973 ; Umanskii et al., 1974) très peu d'études ont cherché à déterminer le rôle des acides gras dans la nutrition de ces bactéries. Poznanski et al. (1968) précisent que certaines souches de $S$. lactis peuvent utiliser de grandes quantités d'acide oléique pendant leur croissance. D'autres souches de streptocoques du groupe $\mathrm{N}$ et les lactobacilles seraient au contraire inhibés par ce même composé. Ces auteurs ont montré que les levains mixtes utilisés pour la fabrication de crèmes, $S$. thermophilus ou L. bulgaricus peuvent être inhibés par l'acide caprique. Ce composé inhibe aussi l'activité protéolytique de certaines souches de $S$. diacetylactis (Poznanski et al., 1968) ou de L. bulgaricus (Trovarelli, 1974). L'effet inhibiteur des acides gras sur la croissance des streptocoques, des lactobacilles et des Leuconostoc a aussi été noté par Kulshrestha et Marth (1975 a et b).

\section{CONCLUSIONS}

Le traitement industriel de quantités journalières de lait de plus en plus importantes par unité de fabrication exige, d'une part, que le lait soit un milieu de culture le plus constant possible pour les bactéries lactiques mises en œuvre et que, d'autre part, le métabolisme de celles-ci soit bien connu afin de maîtriser les facteurs le régulant et par conséquent de maîtriser leur pouvoir acidifiant ou aromatisant.

Si les mécanismes du catabolisme du lactose et des protéines sont, comme nous l'avons montré dans cette revue, mieux connus que dans le passé, il reste encore de nombreuses recherches à effec- 
tuer. En particulier, le métabolisme des sucres de Streptococcus thermophilus et des différents lactobacilles semble avoir été moins profondément étudié que celui des streptocoques mésophiles. D'autre part, le rôle des systèmes protéinase-exopeptidase dans la nutrition azotée devrait être mieux précisé afin de connaître le mécanisme exact de l'utilisation des protéines par les bactéries lactiques cultivant dans le lait. Comme le notent Thomas et Mills (1982), ceci nécessite encore de préciser la localisation exacte et la spécificité d'action des enzymes réellement impliquées et de caractériser de façon détaillée les systèmes de transport des acides aminés et des peptides impliqués.

Le deuxième axe de recherche est lié à la nature des bactéries lactiques elles-mêmes. Il est beaucoup plus complexe car il est en relation avec l'instabilité génétique de certains caractères d'acidification ou de protéolyse. L'induction de mutants plus actifs devrait aussi être recherchée. Le rôle des plasmides, du fait des informations génétiques qu'ils portent, ouvre un champ très large à de nouvelles études. On peut donc penser que dans le futur, on pourra transférer génétiquement des propriétés supplémentaires aux bactéries lactiques et ainsi obtenir des levains parfaitement adaptés aux technologies (Sharpe, 1979).

Enfin, les bactéries lactiques n'étant pas généralement utilisées en souche pure, les recherches devraient porter aussi sur les phénomènes de symbiose et d'antibiose dans les cultures associées, pour lesquels nous ne possédons que trop peu de données.

\section{Remerciements}

L'auteur remercie MM. J. P. Accolas et J. L. Bergère pour les conseils donnés au cours de la rédaction du manuscrit.

\section{Bibliographie}

Accolas (J. P.), Veaux (M.) et Auclair (J.) (1971). - Etude des interactions entre diverses bactéries lactiques thermophiles et mésophiles, en relation avec la fabrication des fromages à pâte cuite. Le Lait, 51, 249-272.

Accolas (J. P.), Hemme (D.), Desmazeaud (M. J.), Vassal (L.), Bouillanne (C.) et Veaux (M.) (1980). - Les levains lactiques thermophiles : propriétés et comportement en technologie laitière. Une revue. Le Lait, 60, 487-524.

AKPEMAdO (K. M.) and BRACouART (P.A.) (1983). - Uptake of branched - chain amino acids by Streptococcus thermophilus. Appl. Environm. Microbiol., 45, $136-140$.

ANDERS (R. F.) and JAGo (G. R.) (1970). - The effect of fatty acids on the metabolism of pyruvate in lactic acid streptococci. J. Dairy Res., 37, 445-456.

ANDERS (R. F.), Jonas (H. A.) and JAGo (G. R.) (1970). - A survey of the lactate dehydrogenase activities in group $\mathrm{N}$ streptococci. Aust. J. Dairy Technol., 25, 73-76. 
Anderson (D. G.) and Mc KaY (L. L.) (1977). - Plasmids loss of lactose metabolism, and appearance of partial and full lactose-fermenting revertants in Streptococcus cremoris $\mathrm{B}_{1}$. J. Bacteriol., 129, 367-377.

ANRAKU (Y.) (1978). - Active transport of amino acids. In: Bacterial transport. Ed. Rosen (B. P.), Marcel Dekker, Inc. New York.

ANRAKU (Y.) (1980). - Transport and utilization of amino acid by bacteria. In: Microorganisms and nitrogen sources. Ed. Payne (J.W.), Chichester. J. Wiley.

ARCHIBALD (F. S.) and FRIDovich (I.) (1981 a), - Manganese and defenses against oxygen toxicity in Lactobacillus plantarum. J. Bacteriol., 145, 442-451.

ARCHibald (F. S.) and Fridovich (I.) (1981 b). - Manganese, superoxide dismutase, and oxygen tolerance in some lactic bacteria. J. Bacteriol., 146, 928-936.

ARchibald (F.S.) and Fridovich (I.) (1982). - Investigations of the state of the manganese in Lactobacillus plantarum. Arch. Bioch. Biophys., 215, 589-596.

Argyle (P. J.), Mathison (G. E.) and Chandan (R. C.) (1976). - Production of cell-bound proteinase by Lactobacillus bulgaricus and its location in the bacterial cell. J. Appl. Bacteriol., 41, 175-184.

Baudet (P.), RöSsler (R.) et Cherbuliez (E.) (1960). - Strépogénines de la caséine. II. Valyl-glutaminyl-valyl-leucyl-prolyl-prolyl-prolyl-valyl-prolyl-glutaminyllysine (TB- $\gamma 26)$ et alanyl-glutaminyl-prolyl-valyl-prolyl-tyrosyl-alanyl-prolylprolyl-valyl-glutaminyl-arginine (TB- $\gamma 2 / 5)$. Helv. Chim. Acta, 43, 1795-1820.

Bissett (D. L.) and ANDERson (R. L.) (1974). - Lactose and D-galactose metabolism in group $\mathrm{N}$ streptococci. Presence of enzymes for both the D-galactose 1-phosphate and D-tagatose 6-phosphate pathways. J. Bacteriol., 117, 318-320.

Boulllanne (C.) et Desmazeaud (M. J.) (1980). - Etude de quelques caractères de souches de Streptococcus thermophilus utilisées en fabrication de yoghourt et proposition d'une méthode de classement. Le Lait, 60, 458-473.

Boulllanne (C.) et Desmazeaud (M. J.) (1981). - Classement de souches de Lactobacillus bulgaricus selon quelques caractères utilisés en fabrication du yoghourt. Association avec Streptococcus thermophilus. Sciences Aliments, 1, 7-17.

Bracouart (P.) et LoRient (D.) (1977). - Effet des acides aminés sur la croissance de Streptococcus thermophilus. Milchwissenschaft, 32, 221-224.

Bracouart (P.), Lorient (D.) et Allais (C.) (1978). - Effet des acides aminés sur la croissance de Streptococcus thermophilus. II. Etude sur cinq souches. Milchwissenschaft, 33, 341-344.

Bracouart (P.) et LoRient (D.) (1979). - Effet des acides aminés et peptides sur la croissance de Streptococcus thermophilus. III. Peptides comportant Glu, His et Met. Milchwissenschaft, 34, 676-679.

Britton (L.), Malinowski (D. P.) and Fridovich (I.) (1978). - Superoxide dismutase and oxygen metabolism in Streptococcus faecalis and comparison with other microorganisms. J. Bacteriol., 134, 229-236.

Broome (M. C.), Thomas (M. P.), Hillier (A. J.) and JAGo (G. R.) (1980). - Pyruvate dehydrogenase activity in group $\mathrm{N}$ streptococci. Austr. J. Biol. Sci., 33, 15-25.

CAstberg (H. B.) and Morris (H. A.) (1976). - Degradation of milk proteins by enzymes from lactic acid bacteria used in cheese making. A review. Milchwissenschaft, 31, 85-90.

Chandan (R. C.), Argyle (P. J.) and Mathison (G. E.) (1982). - Action of Lactobacillus bulgaricus proteinase preparations on milk proteins. J. Dairy Sci., 65, 1408-1413.

Chassy (B. M.), Gibson (E. M.) and GuifFrida (A.) (1978). - Evidence for plasmidassociated lactose metabolism in Lactobacillus casei subsp. casei. Curr. Microbiol., 1, 141-144. 
Chopin (A.) et Langella (P.) (1982). - Analogies de profils plasmidiques chez les streptocoques du groupe N. Le Lait, 62, 705-719.

Citti (J.E.), SANDine (W.E.) and Elliker (P. R.) (1965). - $\beta$-galactosidase of Streptococcus lactis. J. Bacteriol., 89, 937-942.

Cogan (T. M.) (1978). - Determination of growth rates of lactic starter cultures. Irish J. Food Sci. Technol., 2, 105-115.

Cogan (T. M.) (1980). - Les levains lactiques mésophiles. Une revue, Le Lait, $60,397-425$.

CoGan (T.M.) (1981). - Constitutive nature of the enzymes of citrate metabolism in Streptococcus lactis subsp. diacetylactis. J. Dairy Res., 48, 489-4,95.

Cogan (T. M.), O'Dowd (M.) and MELlerick (D.) (1981). - Effects of pH and sugar on acetoin production from citrate by Leuconostoc lactis. Appl. environm. Microbiol., 41, 1-8.

CoHen (G. N.) and Monod (J.) (1957). - Bacterial permeases. Bacteriol. Rev., 21 , 169-194.

Coles (R.S.) and Lichstein (H.) (1963). - The inhibition of malic enzyme of Lactobacillus arabinosus 17-5 by oleic acid. I. Observations on the reaction. Arch. Biochem. Biophys., 103, 186-190.

Collins (E. B.) (1972). - Biosynthesis of flavor compounds by microorganisms. J. Dairy Sci., 55, 1022-1028.

Collins (L. B.) and Thomas (T. D.) (1974). - Pyruvate kinase of Streptococcus lactis. J. Bacteriol., 120, 52-58.

CoRDS (B. R.) and Mc KAY (L. L.) (1974). - Characterization of lactose-fermenting revertants from lactose-negative Streptococcus lactis C2 mutants. J. Bacteriol., $119,830-839$.

Cowman (R. A.), Yoshimura (S.) and Swaisgood (H. E.) (1968). - Proteinase enzyme system of lactic streptococci. III. Substrate specificity of Streptococcus lactis intracellular proteinase. J. Bacteriol., 95, 181-187.

Crow (V. L.) and Thomas (T. D.) (1982). - D-tagatose 1,6-diphosphate aldolase from lactic streptococci: Purification, properties and use in measuring intracellular tagatose 1,6-diphosphate. J. Bacteriol., 151, 600-608.

DACRE (J.C.) and SHARPE (M.E.) (1956). - Catalase production by lactobacilli. Nature, $178,700$.

Davies (F. L.) and Gasson (M. J.) (1981). - Genetics of lactic acid bacteria. J. Dairy Res., 48, 363-376.

DAVIS (J. G.) (1963). - The lactobacilli. II. Applied aspects. In: Progress in Industrial Microbiology, vol. 4, Ed. Hockenhull (D. J. D.), London, Heywood \& Co.

De Man (J. C.), Rogosa (M.) and Sharpe (M. E.) (1960). - A medium for the cultivation of lactobacilli. J. appl. Bacteriol, 23, 130-135.

Demko (G. M.), Blanton (S. J.B.) and Benort (R. E.) (1972). - Heterofermentative carbohydrate metabolism of lactose-impaired mutants of Streptococcus lactis. J. Bacteriol., 112, 1335-1345.

Desmazeaud (M. J.) (1974). - Propriétés générales et spécificité d'action d'une endopeptidase neutre intracellulaire de Streptococcus thermophilus. Biochimie, 56, 1173-1181.

Desmazeaud (M.) et Devoyod (J. J.) (1970). - Action stimulante des microcoques caséolytiques sur les bactéries lactiques thermophiles. Mise en évidence de la nature peptidique des substances stimulantes. Ann. Biol. Anim. Bioch. Biophys., 10, 413-430. 
Desmazeaud (M. J.) et Hermier (J. H.) (1972). - Isolement et détermination de la composition qualitative des peptides issus de la caséine, stimulant la croissance de Streptococcus thermophilus. Eur. J. Biochem., 28, 190-198.

Desmazeaud (M. J.) et Hermier (J.) (1973). - Effet de fragments peptidiques du glucagon vis-à-vis de la croissance de Streptococcus thermophilus. Biochimie, $55,679-684$.

Desmazeaud (M. J.) et Juge (M.) (1976). - Caractérisation de l'activité protéolytique et fractionnement des dipeptidases et des aminopeptidases de Streptococcus thermophilus. Le Lait, 56, 241-260.

Desmazeaud (M. J.) and Zevaco (C.) (1976). - General properties and substrate specificity of an intracellular neutral protease from Streptococcus diacetylactis. Ann. Biol, anim. Bioch. Biophys., 16, 851-868.

Desmezeaud (M. J.) and Zevaco (C.) (1977). - General properties and substrate specificity of an intracellular soluble dipeptidase from Streptococcus diacetylactis. Ann. Biol. anim. Bioch. Biophys., 17, 723-736.

Desmazeaud (M. J.) and Zevaco (C.) (1979). - Isolation and general properties of two intracellular aminopeptidases of Streptococcus diacetylactis. Milchwissenschaft, 43, 606-610.

Driessen (F. M.), Kingma (F.) and Stadhouders (J.) (1982), - Evidence that Lactobacillus bulgaricus in yogurt is stimulated by carbon dioxide produced by Streptococcus thermophilus. Neth. Milk Dairy J., 36, 135-144.

Dynon (M. K.), JAGo (G. R.) and Davidson (B.E.) (1972). - The subunit structure of lactate dehydrogenase from Streptococcus cremoris US3. Eur. J. Biochem, 30, 348-353.

Efstathiou (J. D.) and Mc KAy (L. L.) (1976). - Plasmids in Streptococcus lactis. Evidence that lactose metabolism and proteinase activity are plasmid linked. App. environm. Microbiol., 32, 38-44.

EgGimann (B.) and Bachmann (M.) (1980). - Purification and partial characterization of an aminopeptidase from Lactobacillus lactis. Appl. Environm. Microbiol., 40, 876-882.

El Soda (M.) and Desmazeaud (M. J.) (1981). - General properties of a new ribosomal aryl-peptidyl amidase in Lactobacillus casei. Agric. Biol. Chem., $45,1693-1700$.

El Soda (M.) et Desmazeaud (M. J.) (1982). - Les peptide-hydrolases des lactobacilles du groupe Thermobacterium. I. Mise en évidence des activités chez Lactobacillus helveticus, L. acidophilus, L. lactis et L. bulgaricus. Can. J. Microbiol., 28, 1181-1188,

El Soda (M.), Bergère (J. L.) and Desmazeaud (M. J.) (1978 a). - Detection and localization of peptide hydrolase in Lactobacillus casei. J. Dairy Res., 45, 519-524.

El Soda (M.), Desmazeaud (M. J.) and Bergère (J. L.) (1978 b). - Peptide hydrolases of Lactobacillus casei. Isolation and general properties of various peptidases activities. J. Dairy Res., 45, 445-455.

El Soda (M.), Zeyada (N.), Desmazeaud (M. J.), Mashaly (R.) et Ismail (A.) (1982). Les peptide-hydrolases des lactobacilles du groupe Betabacterium. Mise en évidence chez Lactobacillus brevis, $L$. fermentum, $L$. buchneri et $L$. cellobiosus. Sciences Aliments, 2, 261-273.

El Soda (M.), Said (H.), Desmazeaud (M. J.), Mashaly (R.) and Ismail (A.) (1983). The intracellular peptide-hydrolases of Lactobacillus plantarum. Comparison with Lactobacillus casei. Le Lait, 63, 1-14.

EXTERKATE (F. A.) (1975). - An introductory study of the proteolytic system of Streptococcus cremoris strain H.P. Neth Milk Dairy J., 29, 303-318. 
Exterkate (F.A.) (1976 a). - The proteolytic system of a slow lactic-acid producing variant of Streptococcus cremoris H.P. Neth. Milk Dairy J., 30, 3-8.

Exterkate (F. A.) (1976 b). - Comparison of strains of Streptococcus cremoris for proteolytic activities associated with the cell wall. Neth Milk Dairy J., 30, $95-105$.

EXTERKATE (F. A.) (1977). - Pyrrolidone carboxylyl peptidase in Streptococcus cremoris. Dependence on an interaction with membrane components. J. Bacteriol., 129, 1281-1288.

EXTERKATE (F.A.) (1979). - Effect of membrane perturbing treatments on the membrane-bound peptidases of Streptococcus cremoris H.P. J. Dairy Res., $46,473-484$.

Exterkate (F. A.) (1981). - Membrane-bound peptidases in Streptococcus cremoris. Neth. Milk Dairy J., 35, 328-332.

Ezzat (N.), El Soda (M.), Desmazeaud (M. J.) and Ismail (A.) (1982). - Peptide hydrolases from the Thermobacterium group of lactobacilli. II. Physiological factors and enzyme production. Milchwissenschaft, 37, 666-668.

FarRow (J.A. E.) and GARvie (E. I.) (1979). - Strains of Streptococcus lactis which contain $\beta$-galactosidase. J. Dairy Res., 46, 121-125.

Faust (P. J.) and VANDEMark (P. J.) (1970). - Phosphorylation coupled to NADH oxidation with fumarate in Streptococcus faecalis $10 \mathrm{Cl}$. Arch. Biochem. Biophys., 137, 392-398.

Felton (E. A.), Evans (J. B.) and Niven (C. F. Jr) (1953). - Production of catalase by the pediococci. J. Bacteriol., 65, 481-482.

FrIDOvich (I.) (1979). - Superoxide and superoxide dismutases. In: Advances in organic biochemistry. Ed. Eichhorn (G. L.) and Marzilli (L. G.), New York. Elsevier.

Gallin (J. I.) and VandemaRK (P. J.) (1964). - Evidence for oxidative phosphorylation in Streptococcus faecalis. Biochem. Biophys. Res. Comm., 17, 630-635.

GARVIE (E. I.) (1978). - Lactate dehydrogenases of Streptococcus thermophilus. J. Dairy Res., 45, 515-518.

GaRvie (E. I.) (1980). - Bacterial lactate dehydrogenases. Microbiol. Rev., 44, 106-139.

Gerwin (B. I.), Stein (W. H.) and Moore (S.) (1966). - On the specificity of streptococcal proteinase. J. Biol. Chem., 241, 3331-3339.

Gilliland (S. E.), SPeck (M. L.) and Woodard (J. R. Jr) (1972), - Stimulation of lactic streptococci in milk by $\beta$-galactosidase, Appl. environm. Microbiol., 23, 21-25.

Götz (F.), Sedewitz (B.) and ElstNer (E. F.) (1980 a). - Oxygen utilization by Lactobacillus plantarum. I. Oxygen consuming reactions. Arch. Microbiol., 125, 209-214.

Götz (F.), Elstner (E. F.), Sedewitz (B.) and Lengfelder (E.) (1980 b). - Oxygen utilization by Lactobacillus plantarum. II. Superoxide and superoxide dismutation. Arch. Microbiol., 125, 215-220.

GREenBerg (N. A.) and MAHoNEY (R. R.) (1982), - Production and characterization of $\beta$-galactosidase from Streptococcus thermophilus. J. Food Sci., 47, 18241828, 1835.

Gudkov (A. V.), Perfil'ev (G. D.), Gudkov (S. A.) and Kravchenko (I. D.) (1982). Effect of copper and iron ions on growth and rate of acid production of the microflora of cheese starters. Dairy Sci. Abstr., 44, 458.

Guss (M. L.) and Delwiche (E. A.) (1954), - Streptococcus thermophilus. J. Bacteriol., 67, 714-717. 
HARVEY (R. J.) and Collins (E. B.) (1961). - Role of citritase in acetoin formation by Streptococcus diacetylactis and Leuconostoc citrovorum. J. Bacteriol., 82, 954-959.

HARVEY (R. J.) and Coluins (E. B.) (1962). - Citrate transport system of Streptococcus diacetylactis. J. Bacteriol., 83, 1005-1009.

HARvey (R.J.) and Collins (E.B.) (1963). - The citritase of Streptococcus diacetylactis. J. Biol. Chem., 238, 2648-2653.

Hemme (D.), WAHL (D.) et NARdi (M.) (1980 a). - Variations de l'équipement enzymatique de Streptococcus thermophilus. Le Lait, 60, 111-129.

Hemme (D.), NARDi (M.) et JetTe (D.) (1980 b). - $\beta$-galactosidases et phospho- $\beta$ galactosidases de Streptococcus thermophilus. Le Lait, 60, 595-618.

Hemme (D.), NARDi (M.) et WAHL (D.) (1981 a). - Propriétés des lacticodéshydrogénases de Streptococcus thermophilus indépendantes du fructose 1,6diphosphate. Le Lait, 61, 1-18.

Hemme (D.), Schmal (V.) and Auclair (J. E.) (1981 b). - Effect of the addition of extracts of thermophilic lactobacilli on acid production by Streptococcus thermophilus in milk. J. Dairy Res., 48, 139-148.

Hillier (A.J.), Rice (G. H.) and JAGo (G. R.) (1978). - Transport of purine bases by Streptococcus lactis. J. Dairy Res., 45, 277-282.

HoFER (F.) (1977). - Involment of plasmids in lactose metabolism in Lactobacillus casei suggested by genetic experiments. FEMS Microbiol. Lett., 1, 167-169.

Holzer (H.), Betz (H.) and EBNER (E.) (1975). - Intracellular proteinases in microorganisms. Curr. Top. Cell. Regul., 9, 103-156.

Iaccarino (M.), Guardiola (J.) and Felice (M. DE) (1980). - Genetics of amino acid transport. In: Microorganisms and nitrogen sources. Ed. Payne (J. W.), Chichester. J. Wiley.

INGRAM (M.) (1975). - The lactic acid bacteria. A broad review. In: Lactic acid bacteria in beverages and food. Ed. Carr (J. G.), Cutting (C. V.) and Whiting (G. C.), London. Academic Press.

INGRAM (M.) and Luthi (H.) (1961). - Microbiology of fruit juices. In: Fruit and vegetable processing technology. Ed. Tressler (D. K.) and Joslyn (M. A.), Westport. Avi publ. Co.

JAGo (G. R.), Nichol (L. W.), O'DEA (K.) and SAWYER (W. H.) (1971). - Physicochemical studies on the lactate dehydrogenase of Streptococcus cremoris US $_{3}$. The effects of modifiers. Biochim. Biophys. Acta, 250, 271-285.

JoHnson (K. G.) and Mc DoNALD (I. J.) (1974). - $\beta$-D-phosphogalactoside galactohydrolase from Streptococcus cremoris HP. Purification and enzyme properties. J. Bacteriol., 117, 667-674.

JoNAS (H. A.), ANDERS (R. F.) and JAGO (G. R.) (1972). - Factors affecting the activity of the lactate dehydrogenase of Streptococcus cremoris. J. Bacteriol., 111, 397-403.

KempLeR (G. M.) and Mc KaY (L. L.) (1979). - Characterization of plasmid deoxyribonucleic acid in Streptococcus lactis subsp. diacetylactis. Evidence for plasmid-linked citrate utilization. Appl. Environm. Microbiol., 37, 316-323.

KeMPLER (G. M.) and Mc KaY (L. L.) (1981). - Biochemistry and genetics of citrate utilization in Streptococcus lactis ssp. diacetylactis. J. Dairy Sci., 64, 15271539.

KolodKIN (A. M.) (1979). - Resistance to copper of lactic acid bacteria used in cheese starters. Dairy Sc. Abstr., 41, 171.

KuHL (S. A.), LARSEN (L. D.) and Mc KAY (L. L.) (1979). - Plasmid profiles of lactose-negative and proteinase-deficient mutants of Streptococcus lactis C 10, $\mathrm{ML}_{3}$ and M 18. Appl. Environm. Microbiol., 37, 1193-1195. 
Kulshrestha (D. C.) and Marth (E. H.) (1975 a). - Inhibition of Streptococcus lactis and Salmonella typhimurium by mixtures of some volatile and nonvolatile compounds associated with milk. J. Milk Food Technol., 38, 138-141.

Kulshrestha (D. C.) and Marth (E. H.) (1975 b). - Some volatile and non-volatile compounds associated with milk and their effects on certain bacteria. A review. J. Milk Food Technol., 38, 604-620.

Kümmel (A.), Behrens (G.) and Gottschalk (G.) (1975). - Citrate lyase from Streptococcus diacetylactis. Association with its acetylating enzyme. Arch. Microbiol., 102, 111-116.

Kundig (W.), Ghosh (S.) and Roseman (S.) (1964). - Phosphate bound to histidine in a protein as an intermediate in a novel phospho-transferase system. Proc. Nat. Acad. Sci., 52, 1067-1074

Law (B. A.) (1977). - Dipeptide utilization by starter streptococci. J. Dairy Res. 44, 309-317.

LaW (B. A.) (1978). - Peptide utilization by group N streptococci. J. Gen. Micro biol., 105, 113-118.

LAW (B. A.) (1979), - Extracellular peptidases in groupe N streptococci used as cheese starters. J. Appl. Bacteriol., 46, 455-463.

Law (B. A.) (1982). - Cheeses. In: Fermented Foods, vol. 7. Ed. Rose (A. H.) London. Academic Press.

LaW (B A.), Sezgin (E.) and Sharpe (M. E.) (1976). - Amino acid nutrition of some commercial cheese starters in relation to their growth in peptone supplemented whey media. J. Dairy Res., 43, 291-300.

LAW (B. A.) and SHARPE (M. E.) (1978). - Streptococci in the dairy industry. In: Streptococci. Ed. Skinner (F. A.) and Quesnel (L. B.), London. Academic Press.

Lawrence (R. C.), Thomas (T. D.) and Terzaghi (B. E.) (1976). - Cheese starters. J. Dairy Res., 43, 141-193.

LEACH (F. R.) and SNell (E. E.) (1960), - The absorption of glycine and alanine and their peptides by Lactobacillus casei. J. Biol. Chem,, 235, 3523-3531.

Ledesma (O. V.), de Ruiz Holgado (A. P.), Olivier iG.), de Giori (G. S.), Raibaud (P.) and GALPIN (J. V.) (1977). - A synthetic medium for comparative nutritional studies of lactobacilli. J. Appl. Bacteriol., 42, 123-133.

Lee (R.), Molskness (T.), SAndine (W. E.) and Elliker (P. R.) (1973). - Carbohydrate metabolism in lactic streptococci. Fate of galactose supplied in free or disaccharide form. Appl. Environm. Microbiol., 26, 951-958.

LEES (G. J.) and JAGO (G. R.) (1976). - Acetaldehyde. An intermediate in the formation of ethanol from glucose by lactic acid bacteria. J. Dairy Res., $43,63-73$

Lehninger (A. L.) (1977). - Biochimie, $2^{e}$ éd., Paris, Flammarion.

Mc Feters (G. A.), SANDine (W. E.), Becker (R. R.) and Elliker (P. R.) (1969). Some factors affecting association-dissociation of $\beta$-galactosidase from Streptococcus lactis 7962. Can. J. Microbiol., 15, 105-110.

Mc KAY (L. L.) and Baldwin (K. A.) (1975), - Plasmid distribution and evidence for a proteinase plasmid in Streptococcus lactis C2. Appl. Environm. Microbiol., 29, 546-548.

Mc Kay (L. L.), Walter (L. A.), Sandine (W. E.) and Elliker (P. R.) (1969). Involvement of phosphoenol-pyruvate in lactose utilization by group $\mathrm{N}$ streptococci. J. Bacteriol., 99, 603-610. 
Mc Kay (L.), Miller (A.), Sandine (W. E.) and Elliker (P. R.) (1970). - Mechanisms of lactose utilization by lactic acid streptococci. Enzymatic and genetic analysis. J. Bacteriol., 102, 804-809.

Mc Kay (L. L.), SANdine (W. E.) and Elliker (P. R.) (1971). - Lactose utilization by lactic acid bacteria. A review. Dairy Sci. Abst., 33, 493-499.

MELLERICK (D.) and COGAN (T. M.) (1981). - Introduction of some enzymes of citrate metabolism in Leuconostoc lactis and other heterofermentative lactic acid bacteria. J. Dairy Res., 48, 497-502.

Mercier (J. C.), Ribadeau-Dumas (B.) and Grosclaude (F.) (1973). - Amino-acid composition and sequence of bovine $\chi$-casein. Neth. Milk Dairy J., 27, 313-322.

MERRIFIELD (R. B.) and Woolley (D. W.) (1958). - The synthesis of peptides with strepogenin activity. J. Amer. Chem. Soc., 80, 6635-6639.

Millis (O.E.) and THOMAs (T.D.) (1978). - Release of cell wall-associated proteinase(s) from lactic streptococci. N. Z. J. Dairy Sci. Technol., 13, 209-215.

Mnls (O. E.) and Thomas (T. D.) (1981). - Nitrogen sources for growth of lactic streptococci in milk. N. Z. J. Dairy Sci. Technol., 16, 43-55.

Morse (M. L.), Hill (K. L.), Egan (J. B.) and Hengstenberg (W.) (1968). - Metabolism of lactose by Staphylococcus aureus and its genetic basis. J. Bacteriol., 95, 2270-2274.

Mou (L.), Mulvena (D. P.), Jonas (H. A.) and JAgo (G. R.) (1972). - Purification and properties of nicotinamide adenine dinucleotide-dependant D and Llactate dehydrogenases in a group N Streptococcus, J. Bacteriol., 111, 392-396.

Mou (L.), Sullivan (J. J.) and Jago (G. R.) (1975). - Peptidase activities in group N streptococci. J. Dairy Res., 42, 147-155.

OhmiYa (K.) and SATo (Y.) (1975). - Purification and properties of intracellular proteinase from Streptococcus cremoris. Appl. Microbiol., 30, 738-745.

ORAM (J. D.) and ReITER (B.) (1966). - The inhibition of streptococci by lactoperoxidase, thiocyanate and hydrogen peroxide. Biochem. J., 100, 373-381.

Payne (J.W.) (1976). - Peptides and microorganisms. Adv. microb. Physiol., 13, 55-113.

PAyne (J. W.) and Tuffnell (J. M.) (1980). - Assays for amino acids, peptides and proteins. In: Microorganisms and nitrogen sources. Ed. Payne (J. W.), Chichester, J, Wiley.

Pearce (L. E.), Skipper (N. A.) and Jarvis (B. D. W.) (1974). - Proteinase activity in slow lactic acid producing variants of Streptococcus lactis. Appl. Environm. Microbiol., 27, 933-937.

Peters (V. J.), Prescott (J. M.) and Snell (E. E.) (1953). - Peptides and bacterial growth. IV. Histidine peptides as growth factors for Lactobacillus delbrueckii 9649. J. Biol. Chem., 202, 521-532.

PoZnanski (S), SURAZYNSKi (A.) et D'ObYRn (T.) (1968). - Activité de fermentation et de protéolyse de certaines souches de bactéries lactiques en présence d'acides gras. Le Lait, 48, 261-274.

PREMI (L.), SANDine (W E.) and ElLIKER (P. R.) (1972). - Lactose-hydrolysing enzymes of Lactobacillus species. Appl. Environm. Microbiol., 24, 51-57.

Rabier (D.) et Desmazeaud (M. J.) (1973). - Inventaire des différentes activités peptidasiques intracellulaires de Streptococcus thermophilus. Purification et propriétés d'une dipeptide-hydrolase et d'une aminopeptidase. Biochimie, $55,389-404$.

Ramasamy (V.) and Natarajan (A.M.) (1981), - Purine and pyrimidine requirements of active lactic and bacteria. Dairy Sci. Abstr., 43, 283. 
REITER (B.) and Oram (J. D.) (1962). - Nutritional studies on cheese starters. I. Vitamin and amino acid requirements of single strain starters. J. Dairy Res., 29, 63-77.

Reiter (B.) and Møller-Madsen (A.) (1963). - Cheese and butter starters. J. Dairy Res., 30, 419-456.

Rice (G. H.), Stewart (F. H. C.), Hillier (A. J.) and Jago (G. R.) (1978). - The uptake of amino acids and peptides by Streptococcus lactis. J. Dairy Res., $45,93-107$

Ritchey (T. W.) and Seeley (H. W. Jr) (1976). - Distribution of cytochromelike respiration in streptococci. J. Gen. Microbiol., 93, 195-203.

Rogosa (M.) (1974). - Lactobacillus: In: Bergey's Manual of Determinative Bacteriology. 8th ed., Buchanan (R. E.) and Gibbons (N.E.). Ed. The Williams and Wilkins Co, Baltimore.

Sawula (R. V.), ZamenhoF (S.) and ZamenhoF (P. J.) (1974). - Degradation of thymidine by Lactobacillus acidophilus. J. Bacteriol., 117, 1358-1360.

Schmidt (R. H.), Morris (H. A.), Castberg (H. B.) and Mc Kay (L. L.) (1976). Hydrolysis of milk proteins by bacteria used in cheese making. J. Agric. Food Chem., 24, 1106-1113.

Schmidt (R. H.), Morris (H. A.) and Mc KAY (L. L.) (1977 a). - Cellular location and characteristics of peptidase enzymes in lactic streptococci. J. Dairy Sci., 60, 710-717.

SchMidT (R. H.), MORRIS (H. A.) and Mc KAY (L. L.) (1977 b). - Species differences and effect of incubation time on lactic streptococcal intracellular proteolytic enzyme activity. J. Dairy Sci., 60, 1677-1682.

Selby Smith (J.), Hillier (A. J.), Lees (G. J.) and Jago (G. R.) (1975). - The nature of the stimulation of the growth of Streptococcus lactis by yeast extract. J. Dairy Res., 42, 123-138.

Sharpe (M. E.) (1979). - Lactic acid bacteria in the dairy industry. J. Soc. Dairy Technol., 32, 9-18.

SiJPESTEIJN (A. K.) (1970). - Induction of cytochrome formation and stimulation of oxidative dissimilation by hemin in Streptococcus lactis and Leuconostoc mesenteroides. Antonie Leeuwenhoek, 36, 335-348.

Singh (M.) and SRERE (P.) (1975). - Purification and properties of citrate lyase from Streptococcus diacetylactis. J. Biol. Chem., 250, 5818-5825.

Smalley (A. J.), Jahrling (P.) and Vandemark (P. J.) (1968). - Molar growth yields as evidence for oxidative phosphorylation in Streptococcus faecalis strain 10C1. J. Bacteriol., 96, 1595-1600.

SMILEY (M. B.) and FRYDER (V.) (1978). - Plasmids, lactic acid production, and $\mathrm{N}$-acetyl-D-glucosamine fermentation in Lactobacillus helveticus subsp. jugurti. Appl. Environm. Microbiol., 35, 777-781.

SøRHAUG (T.) and Solberg (P.) (1973). - Fractionation of dipeptidase activities of Streptococcus lactis and dipeptidase specificity of some lactic acid bacteria. Appl. Environm. Microbiol., 25, 388-395.

SPRINCE (H.) and Wooley (D. W.) (1945). - The occurence of the growth factor strepogenin in purified proteins. J. Amer. Chem. Soc., 67, 1734-1736.

Stadhouders (J.) and Veringa (H. A.) (1973), - Fat hydrolysis by lactic acid bacteria in cheese. Neth. Milk Dairy J., 27, 77-91.

Thomas (M. P.), Broome (M. C.), Hillier (A.J.) and JAGo (G. R.) (1979). - A comparative study of the formation of acetate from pyruvate in group $\mathrm{N}$ streptococci. Austr. J. Dairy Technol., 34, 97-101. 
Thomas (T. D.) (1975). - Tagatose-1,6-diphosphate activation of lactate dehydrogenase from Streptococcus cremoris. Biochem. Biophys. Res. Comm., 63, 1035-1042.

THomas (T. D.) (1976 a). - Regulation of lactose fermentation in group N streptococci. Appl. Environm. Microbiol., 32, 474-478.

Thomas (T.D.) (1976 b). - Activator specificity of pyruvate kinase from lactic streptococci. J. Bacteriol., 125, 1240-1242.

Thomas (T. D.) and Mills (O. E.) (1981). - Proteolytic enzymes of starter bacteria. Neth. Milk Dairy J., 35, 255-273.

Thomas (T. D.), JARvis (B. D. W.) and SKIPPER (N. A.) (1974). - Localization of proteinase(s) near the cell surface of Streptococcus lactis. J. Bacteriol., 118, 329-333.

Thomas (T. D.), TURner (K. W.) and CRow (V. L.) (1980). - Galactose fermentation by Streptococcus lactis and Streptococcus cremoris. Pathways, products and regulation. J. Bacteriol., 144, 672-682.

Thompson (J.) (1978), - In vivo regulation of glycolysis and characterization of sugar: phosphotransferase systems in Streptococcus lactis. J. Bacteriol., 136, 465-476.

Thompson (J+) (1979). - Lactose metabolism in Streptococcus lactis. Phosphorylation of galactose and glucose moieties in vivo. J. Bacteriol., 140, 774-785.

THompson (J.) (1980). - Galactose transport systems in Streptococcus lactis. J. Bacteriol., 144, 683-691.

Thompson (J.) and Thomas (T. D.) (1977). - Phosphoenolpyruvate and 2-phosphoglycerate: endogenous energy source(s) for sugar accumulation by starved cells of Streptococcus lactis. J. Bacteriol., 130, 583-595.

Thompson (J.), TURner (K. W.) and Thomas (T. D.) (1978). - Catabolite inhibition and sequential metabolism of sugars by Streptococcus lactis. J. Bacteriol., $133,1163-1174$.

Tinson (W.), Hillier (A. J.) and Jago (G. R.) (1982 a). - Metabolism of Streptococcus thermophilus. I. Utilization of lactose, glucose and galactose. Aust. J. Dairy Technol., 37, 8-13.

Tinson (W.), Hillier (A. J.) and JAGo (G. R.) (1982 b), - Metabolism of Streptococcus thermophilus. 4. Utilization of pyruvate and citrate. Aust. J. Dairy Technol., 37, 22-25.

Tiwari (K. P.), PANDEY (A.) and Mishra (N.) (1980). - Lactic acid production from molasses by Lactobacillus bulgaricus $\mathrm{AU}$ in presence of $\mathrm{U}, \mathrm{Th}, \mathrm{Zr}$ and T1. Zntr. Bkt. Par. I. Hyg., II, 135, 226-229.

Trovarelli (G.) (1974). - Effect of some fatty acids on cultures. Dairy Sci. Abstr., $36,596$.

TURner (K. W.) and THomas (T. D.) (1975). - Uncoupling of growth and acid production in lactic streptococci. N. Z. J. Dairy Sci. Technol., 10, 162-167.

Umanski (M. S.), Borovkova (Yu. A.) and Klimovski (I. I.) (1977). - Lipolytic capacity of lactic acid bacteria and its determination in different species. Dairy Sci. Abstr., 39, 54.

VAKIL (J. R.) and SHAHANI (K. M.) (1969). - Carbohydrate metabolism of lactic acid cultures. III. Glycolytic enzymes of Streptococcus lactis and their sensitivity to antibiotics. Can. J. Microbiol., 15, 753-759.

VAKIL (J. R.) and ShahanI (K. M.) (1970). - Carbohydrate metabolism of lactic acid cultures. IV. Glycolytic and HMS pathway enzymes in Streptococcus lactis and their sensitivity to antibiotics. Antonie Leeuwenhoek, 36, 285-295. 
Vankova (J.) (1957). - Motile catalase-producing strains of Lactobacillus delbrueckii. Nature, 179, 204.

Vescovo (M.) and Bottazzi (V.) (1979). - Caratteristiche dei bacilli lattici presenti nelle colture naturali in siero. C. Localizzazione citologica del sistema proteolitico in L. helveticus. Scienza Tec. Latt. Casear., 30, 434-443.

Wallace (D. L.) and HaRmon (L. G.) (1970). - Intracellular protease from Sreptococcus durans. J. Dairy Sci., 53, 394-402.

Westhoff (D. C.) and Cowman (R. A.) (1970). - Influence of the growth medium on the proteinase system of Streptococcus lactis $\mathrm{n}^{\circ}$ 3. J. Dairy Sci., 53, 1286-1287.

Westhoff (D. C.) and Cowman (R. A.) (1971), - Substrate specificity of the intracellular proteinase from a slow acid producing mutant of Streptococcus lactis. J. Dairy Sci., 54, 1265-1269.

WhittenbuR' (R.) (1962). - Two types of catalase-like activity in lactic acid bacteria. Nature, 187, 433-434.

WhitTENBuRY (R.) (1964). - Hydrogen peroxide formation and catalase activity in the lactic acid bacteria. J. Gen. Microbiol., 35, 13-26.

Whittenbury (R.) (1966). - A study of the genus Leuconostoc. Arch. Mikrobiol., $53,317-327$.

WhitTenbury (R.) (1978). - Biochemical characteristics of Streptococcus species. In: Streptococci. Ed. Skinner (F.A.) and Quesnel (L. B.), London. Academic Press.

WuRTz (B.) (1953). - Variation de l'activité catalasique chez un mutant de Streptobacterium plantarum. C.R. Soc. Biol., 147, 478-480.

Zevaco (C.) and Desmazeaud (M. J.) (1980). - Hydrolysis of $\beta$-casein and peptides by intracellular neutral protease of Streptococcus diacetylactis. J. Dairy Sci., 63, 15-24.

Zielke (H.), KNeIfel (H.), WebB (L. E.) and Sseder (C. J.) (1978). - Stimulation of Lactobacilli by aqueous extract of the green alga Scenedesmus acutus 276-3a. Eur. J. Appl. Microb. Biotech., 6, 79-86. 